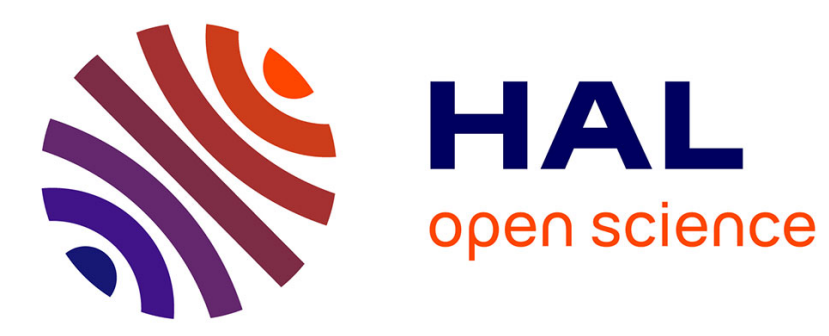

\title{
Prophétie et messianisme politique. La péninsule Ibérique au miroir du Liber Ostensor de Jean de Roquetaillade
}

Martin Aurell

\section{- To cite this version:}

Martin Aurell. Prophétie et messianisme politique. La péninsule Ibérique au miroir du Liber Ostensor de Jean de Roquetaillade. Mélanges de l'Ecole française de Rome. Moyen Age, Temps modernes, 1990, 102 (2), pp.317-361. 10.3406/mefr.1990.3120 . halshs-01305724

\section{HAL Id: halshs-01305724 \\ https://shs.hal.science/halshs-01305724}

Submitted on 22 Apr 2016

HAL is a multi-disciplinary open access archive for the deposit and dissemination of scientific research documents, whether they are published or not. The documents may come from teaching and research institutions in France or abroad, or from public or private research centers.
L'archive ouverte pluridisciplinaire HAL, est destinée au dépôt et à la diffusion de documents scientifiques de niveau recherche, publiés ou non, émanant des établissements d'enseignement et de recherche français ou étrangers, des laboratoires publics ou privés. 


\section{Prophétie et messianisme politique. La péninsule Ibérique au miroir du Liber Ostensor de Jean de Roquetaillade} Martin Aurell

\section{Résumé}

Martin Aurell, Prophétie et messianisme politique. La péninsule Ibérique au miroir du Liber Ostensor de Jean de Roquetaillade, p. 317-361.

Jean de Roquetaillade s'est particulièrement penché sur les événements relatifs à la péninsule Ibérique au milieu du XIVe siècle. Les guerres de la confédération catalano-aragonaise servent à étayer sa croyance dans l'imminence de la fin du monde. Son Liber Ostensor (1356) subit l'influence des écrits prophétiques des joachimites catalans : Arnaud de Villeneuve et Raymond Lulle. Mais contrairement à ces auteurs, l'idée de mission lui est étrangère ; Roquetaillade perçoit l'altérité musulmane ou juive sous un jour négatif. Profondément attaché à la maison de France, il tient un discours péjoratif à l'encontre des comtes de Barcelone. Il décrit également les luttes qui opposent Pierre ler (1350-1369) aux Trasta-mares dans le royaume de Castille ainsi que les malheurs de Blanche de Bourbon. Les meneurs de ces guerres sont affublés d'attributs prophétiques, puisés dans un bestiaire joachimite. Le Liber Ostensor témoigne d'une utilisation politique de la prophétie où le messianisme tient lieu d'idéologie utopique.

\section{Citer ce document / Cite this document :}

Aurell Martin. Prophétie et messianisme politique. La péninsule Ibérique au miroir du Liber Ostensor de Jean de Roquetaillade. In: Mélanges de l'Ecole française de Rome. Moyen-Age, tome 102, $n^{\circ} 2$. 1990. Les textes prophétiques et la prophétie en Occident (XII-XVI siècle) pp. 317-361.

doi : $10.3406 /$ mefr. 1990.3120

http://www.persee.fr/doc/mefr_1123-9883_1990_num_102_2_3120

Document généré le 16/10/2015 


\section{PROPHÉTIE ET MESSIANISME POLITIQUE}

\section{LA PÉNINSULE IBÉRIQUE AU MIROIR DU LIBER OSTENSOR DE JEAN DE ROQUETAILLADE}

Entre mai et septembre 1356, Jean de Roquetaillade rédige le Liber Ostensor, ouvrage aussi impressionnant par ses dimensions que par l'étendue de ses références'. C'est emprisonné au palais des Papes d'Avignon qu'il écrit d'un trait ce livre prophétique. Depuis douze années, ce franciscain, "pauper incarceratus ${ }^{2}$, n'a guère connu que l'univers carcéral $^{3}$ : arraché au couvent d'Aurillac en 1344, il a fréquenté pendant cinq ans les geôles de douze maisons de son ordre; en 1349, il est transféré à la prison du soudan du palais des Papes. Au cours de ces années, les conditions de détention ont été particulièrement dures: à Figeac, il a souffert de la mauvaise réduction d'une fracture à la jambe; à Rioux, il a été enchaîné avec des fers; en 1351, déjà en Avignon, il subit les outrages de son voisin de cellule, Symon Legat, un bénédictin apostat du monastère de Winchcombe, que - à en croire Jean de Roquetaillade - la folic rend démoniaque $^{4}$. La prison devient l'image de l'enfer sur terre. Pour s'en évader, l'écriture semble l'unique recours possible: comme P.-A. Amargier le fait remarquer, seule la parole libère dans cette geôle d'Avignon qui acquiert par là même une dimension emblématique ${ }^{5}$.

1 Bibliothèque Vaticane, fonds Rossiano, ms 753, ci-dessous L.O. Nous avons utilisé pour cette étude la version dactylographiée à partir d'une copie de J. Bignami-Odier de l'U.A. 1011, dirigée par A. Vauchez. La publication de ce travail est actuellement en cours. fo 1 .

2 Pauper incarceratus et orator vester Jo. de Rupecissa, professor indignus, L.O.

${ }^{3}$ Cf. J. Bignami-Odier, Etudes sur Jean de Roquetaillade, Paris, 1962, et la communication de S. Barnay et H. Millet au séminaire de l'U.A. 1011 le 10 juin 1988.

4 L.O. fo $84 \mathrm{~V}^{\circ}-85 \mathrm{r}^{\circ}$.

${ }^{5}$ Cf. sa communication publiée dans ces mêmes actes. 
Pourtant, dès 1355 , ses conditions de vie semblent s'améliorer : cette année une aumône lui est remise ainsi que le livre des prophéties du moine Serge ${ }^{6}$. C'est alors qu'intervient la vision du 9 mai 1356 qui ouvre, de façon superbe, le Liber Ostensor: la Vierge lui apparaît se tenant devant le Temple de Salomon; elle lui montre un livre qui contient la miniature de ce même temple; ses portes présentent à leur tour le dessin de douze cellules. L'effet de miroir est remarquablement réussi par ce triple dédoublement. Le chiffre douze, à forte connotation symbolique, évoque les douze années que Jean de Roquetaillade doit passer en prison dans la douleur et dans les tourments. Notre visionnaire s'aperçoit soudain qu'ayant été enfermé en 1344, il ne lui reste plus que six mois de détention ${ }^{7}$. Cet heureux présage apparaît dans un contexte de relâchement des contraintes carcérales : depuis plusieurs semaines, il voit l'étau se desserrer autour de lui.

L'épisode Symon Legat mis à part, il est évident que Jean de Roquetaillade tirait d'énormes avantages de son transfert en Avignon qui le délivrait des dures geôles et des contempteurs de son ordre. D'ailleurs, sa captivité dans la prison du soudan, située à l'intérieur du palais pontifical, devenu carrefour politique et centre décisionnel de la chrétienté, est loin de le couper du monde extérieur. Elle lui permet, d'une part, d'accéder à une bibliothèque et de tenir sous la main les manuscrits prophétiques qui nourrissent ses élucubrations. Elle lui fait, d'autre part, nouer d'innombrables liens avec les hauts dignitaires de la curie, sans doute par l'entremise du cardinal Talleyrand de Périgord, son protecteur. Le personnel du palais pontifical, ses conversations et ses commentaires sur le devenir des États ne lui sont pas tout à fait étrangers. Or, au milieu du XIVe siècle, les décisions et les missions diplomatiques de ces personnages conditionnent largement l'évolution politique de l'Occident. Jean de Roquetaillade se trouve ainsi aux premières loges du théâtre de l'histoire.

La lecture du Liber Ostensor révèle un homme qui se tient au courant de la vie des États de la péninsule Ibérique et, plus particulièrement, de la couronne d'Aragon et du royaume de Castille. Ces formations politiques sont ravagées, depuis quelques années, par les actions militaires et ce contexte belliqueux aiguise son penchant de visionnaire. L'œuvre de Jean de Roquetaillade baigne dans une atmosphère apocalyptique: la guerre, devenue endémique en Occident, étaye sa croyance de l'imminence de la

${ }^{6}$ L.O. fo $44 \mathrm{r}^{\circ}$ et $84 \mathrm{v}^{\circ}$ et exposé de S. Barnay.

7 L.O. fo 8. 
fin du monde ${ }^{8}$. Déchirés par des luttes intestines, les royaumes d'OutrePyrénées sont un laboratoire de rêve pour la vérification de ses prophéties : ils apportent des données empiriques à une analyse qui se fonde sur une grille imprégnée de joachimisme prophétique et de messianisme politique.

\section{AUTOUR DE LA CONFÉDÉRATION CATALANO-ARAGONAISE : ROIS, SPIRITUELS ET SARRAZINS}

L'œuvre de Jean de Roquetaillade est étroitement liée à la Catalogne pour trois raisons. Elle traduit, d'abord, une bonne connaissance des événements qui s'y déroulent dès la fin du XIII ${ }^{e}$ siècle. Elle subit, ensuite, l'influence des penseurs catalans des années 1280-1320, dont les textes y sont largement cités. Elle exerce, enfin, une profonde influence sur les territoires de la couronne d'Aragon au point que ses habitants auront vite fait de la traduire au catalan' et d'attribuer des origines hispaniques au franciscain auvergnat ${ }^{10}$.

\section{UNE INTERPRÉTATION APOCALYPTIQUE DE LA GUERRE}

Au cours de son long règne, Pierre IV (1336-1387), roi d'Aragon, tente de renforcer le pouvoir de sa maison. Il encourage le développement de structures étatiques. Il essaye de réduire la marge de mancuvre de ces véritables contre-pouvoirs que représentent l'Église et la noblesse dans une monarchie fondée sur un accord tacite des parties. Il insiste sur le caractère divin de sa mission ${ }^{1}$. Une politique de réintégration territoriale

${ }^{8}$ Et de XVI ad XXIII principes ruinam et subjectionem passientur et illud durabit. Gallici, Flandrici, Aragonici, Ispanici inter se discordantes, L.O. fo $8 \mathrm{v}$.

- Cf. le manuscrit 336 de la Bibliothèque de Carpentras, qui contient une traduction catalane du Vademecum et des visions de Jean de Roquetaillade.

10 Dès la fin du XIVe siècle, Francesc Eiximenis en catalanise le nom : Joan de Rocatallada. Cette erreur a persisté y compris sous la plume de $\mathbf{M}$. Menéndez y Pelayo.

$"$ Cf. R. D'Abadal, Pedro el Ceremonioso y los comienzos de la decadencia politica de Cataluña, dans R. MEnÉndez PIDAl (dir.), Historia de España, t. XIV, Madrid, 1966. 
des principautés périphériques au noyau catalan fait également partie de ce programme. Elle concerne principalement le royaume de Majorque, la Sardaigne, la Sicile et le duché d'Athènes.

Jean de Roquetaillade connaît les guerres provoquées par une telle tentative de centralisation. Le cinquième traité du Liber Ostensor commence par la révélation dont aurait naguère fait l'objet un franciscain aragonais. Le jour de Noël 1344 ou $1345^{12}$, ce frère avait reçu l'ordre de quitter son couvent pour la montagne, où il devait prêcher dans deux églises. Après avoir exercé son office dans la messe du matin de l'une d'entre elles, il s'apprêtait à traverser un pont sur le chemin qui le menait à l'autre. Il voulut alors remettre dans sa mémoire le sermon qu'il allait dire sur l'annonce faite aux bergers; il décida donc de l'exposer aux poissons de la rivière: son attitude répond aussi bien à la croyance populaire d'après laquelle les bêtes retrouvent la parole aux fêtes du solstice d'hiver ${ }^{13}$ qu'au modèle hagiographique de saint François. Aussitôt, un vieil ange, à la longue barbe blanche, lui apparaît pour annoncer à son tour la longue prophétie dont l'incipit est Flos devincetur.

\section{La reprise de Majorque (1342-1343 et 1349)}

D'après Jean de Roquetaillade, une phrase de cet oracle pourrait faire allusion à la guerre entre Pierre IV et son cousin Jacques III (13241343), roi de Majorque: «A. Cedar sera renversé par .A. roi avec un autre» ${ }^{14}$. Et de gloser à son sujet: "Au pied de la lettre le roi d'Aragon renversa Jacques, roi des Majorques, l'année 1345, précisément celle où cette prophétie avait été révélée, et il l'expulsa de Majorque. Si ce roi Jacques des Majorques avait eu un nom ou royaume commençant par "a", j'aurais dit qu'A. Cedar était le roi d'Aragon et l'autre .A. le roi des Majorques ${ }^{15}$. Dans deux autres passages de ce manuscrit, il revient sur la

12 Anno a nativitate Domini computando more romane curie M CCC XLVto, ipsa die nativitatis... L.O. fo $33 \mathrm{v}^{\circ}$. Cette prophétie devrait être datée de 1344 n.s. car aussi bien la chancellerie pontificale que l'aragonaise utilisent à l'époque le style de la nativité. À d'autres passages de son œuvre, Jean de Roquetaillade la place en 1345.

${ }^{13}$ Remarque faite par C. Beaune dans son exposé du 22 avril 1988 au séminaire de l'U.A. 1011.

${ }^{14}$.A. Cedar .A. rege cum altero prosternabitur, L.O. fo $33 \mathrm{v}^{\circ}$.

${ }^{15}$ Et quia ad literam rex Aragonie, anno Domini M CCC XLV prosternavit Jacobum, regem Majoricarum, eodem scilicet anno quo hec prophecia reuelata fuit et ipsum de Majorica expulit. Si predictus rex Jacobus Majoricarum habuisset nomen 
même guerre. Au début du huitième traité, notre prophète, qui passe en revue tous les signes des temps advenus en 1345, année du verseau, ne peut manquer d'ajouter : «Et cette année, Jacques, roi des Majorques, fut expulsé de son propre royaume par les Majorquins»16. A la fin de son ouvrage, retraçant la chronologie des dernières décennies, il remarque «Et cette même année (1345), Jacques, roi des Majorques, perdit son royaume, dépouillé par le roi Pierre d'Aragon (...). Et l'année du Seigneur 1345, qui fut l'année de l'indulgence générale à Rome, ou plutôt avant le début de cette année, Jacques, roi des Majorques, mourut au cours de la guerre dans cette île, tué par les agents du roi d'Aragon ${ }^{17}$. En somme, Jean de Roquetaillade a su glaner de ci de là des renseignements fort précis sur le conflit qui sanctionna le retour des Baléares et des comtés de Roussillon et de Cerdagne à la couronne d'Aragon.

Un royaume de Majorque indépendant de la maison de Barcelone existe depuis 1276, date à laquelle Jacques Ier avait procédé au partage de ses terres entre ses enfants. En dépit d'une première guerre annexionniste, il subsiste au cours de la première moitié du XIVe siècle, à la suite du traité d'Argelers (1298). Mais Jacques III, rompant avec le jeu traditionnel des alliances mis en place par ses ancêtres, se rapproche de l'Angleterre et rejette l'hommage qu'il doit au roi de France pour Montpellier: Philippe VI l'abandonne à son propre sort face au roi d'Aragon. Entre 1342 et 1343, Pierre IV profite de cette conjoncture diplomatique pour arracher à son cousin le Roussillon et la Cerdagne par la force des armes et pour occuper les Baléares sans coup férir. Pour subvenir à une expédition, Jacques III vend alors la ville de Montpellier au roi de France et obtient l'appui de la curie d'Avignon : il s'embarque avec ses troupes pour les Baléares, où il perd la vie au cours de la bataille de Llucmajor (1349). Ce sont là les événements décrits avec une certaine fidélité dans le Liber Ostensor. Seule la chronologie - 1344/1345 à la place de 1342-1343 - a été manipulée par Jean de Roquetaillade pour mieux faire entrer la première guerre dans un système temporel où l'année 1345 est un point d'ancrage essentiel.

incipiens per .a. aut si regnum suum inciperet par .a., dixissem quod .a. Cedar fuisset rex Aragonie et alter .a. rex Majoricarum, L.O. fo $37 \mathrm{v}^{\circ}$.

16 Et eodem anno, Jacobus, rex Majoricarum, per Majoricenses expulsus est de regno proprio, L.O. fo 58.

17 Et eodem anno perdidit Jacobus, rex Majoricarum, regnum suum, per regem Petrum Aragonie spoliatus (...). Et anno Domini M CCC L, qui fuit annus generalis indulgencie Rome vel ante anni principium periit in bello Jacobus, rex Majoricarum, infra insulam ipsam, agentibus regis Aragonie interfectus, L.O. fo $147 \mathrm{v}^{\circ}$. 
L'analyse de Roquetaillade paraît plus juste lorsqu'il affirme que Jacques III fut expulsé de ses propres terres par les Majorquins: Pierre IV ne rencontra, en effet, aucune résistance pour la conquête des Baléares. La classe marchande des îles savait l'intérêt qu'elle pouvait tirer du retour à la confédération catalano-aragonaise: elle y profitait de l'infrastructure commerciale que les Catalans avaient établie en Méditerranée, d'une situation privilégiée comme relais entre Barcelone et la Sicile, d'un accès plus facile aux centres de ravitaillement de blé, échappant pour toujours aux tarifs douaniers de la couronne d'Aragon. Il en fut tout autrement dans les comtés de Roussillon et de Cerdagne où la noblesse rurale et le clergé restaient profondément attachés à la maison de Majorque ${ }^{18}$.

\section{L'union de Valence (1347-1348)}

Dans la foulée de la chute de Jacques III, Jean de Roquetaillade mentionne les révoltes contre Pierre IV qui éclatent dans les royaumes de Valence et Aragon entre 1347 et 1348 . Décodant le passage de la prophétie Flos devincetur qui dit «après cela il battra les princes stridents et proches», il affirme que ces mots pourraient s'appliquer à la victoire du roi d'Aragon sur l'union de Valence ${ }^{19}$. Il en fait également allusion dans le douzième traité : «Et l'année 46, il advint l'horrible scandale de l'union de Valence contre le roi d'Aragon, dans laquelle il perdit presque son royaume ${ }^{20}$.

Ce mouvement regroupait l'aristocratie et les conseils urbains de Valence et d'Aragon face à une monarchie affirmant trop fermement ses prérogatives; il fut déclenché par la décision de Pierre IV de nommer sa fille Constance son héritière en dépit de la loi salique. Comme l'affirme Jean de Roquetaillade, le roi faillit perdre son royaume: en 1348, il ne put quitter la prison de Valence qu'en profitant de la confusion provoquée par la peste noire et écrasa les révoltés grâce à l'aide catalane. Au cours de ces événements, l'infant Ferdinand d'Aragon, demi-frère du roi, devenu justicia de Valence, joua un rôle de premier plan à la tête de Valenciens et Aragonais qui voyaient en lui le successeur du roi à la place

18 Cf. A. RIERA Melis, La corona de Aragón y el reino de Mallorca en el primer cuarto del siglo XIV, Madrid-Barcelone, 1986.

19 Maxime quia post vicit rex Aragonie duces stridentes contra eum atque propinquos in Unione Valencie contra ipsum facte, L.O. fo $37 \mathrm{r}^{\circ}$.

${ }^{20}$ Et anno XLVIto accidit horribile scandalum unionis Valencie contra regem Aragonum in qua fere perdidit regnum, L.O. fo 147. 
de Constance: comme nous le verrons plus tard, ce personnage est une pièce maîtresse du système prophétique de Jean de Roquetaillade relatif à la Castille.

\section{La reconquête de la Sardaigne (1352-1354)}

Réfléchissant sur l'oracle «Des guerres champêtres se feront du côté de l'Italie et aussi bien les rivages de la mer que la terre pourriront avec des cadavres ${ }^{21}$, Jean de Roquetaillade parvient à la conclusion qu'il concerne les «deux horribles batailles navales» qui ont opposé le roi d'Aragon et les Vénitiens aux Génois ainsi qu'au soulèvement des Sardes, au siège d'Alghero et à la peste qui avaient coûté vingt-huit mille hommes à Pierre IV ${ }^{22}$. Il fait ici référence à la révolte, encouragée par les juges d'Arborea en 1347, qui risquait de faire perdre aux Catalans ce grenier qui représentait pour eux la Sardaigne. Les habitants de l'île demandaient l'appui de la République de Gênes, tandis que Pierre IV se rapprochait de Venise. Á deux reprises, au cours des batailles du Bosphore (1352) et d'Alghero (1353), la flotte génoise était détruite par Aragonais et Vénitiens. La capitale de la Sardaigne tombait après un long siège au bout duquel ses habitants étaient déportés et remplacés par des Catalans. Tout au long de ce conflit, le Saint-Siège avait agi dans le sens de la pacification : pour assurer sa souveraineté sur la Sardaigne, Pierre IV abandonna finalement ses droits sur la Corse à Clément VI (1342-1352). Des bureaux de la curie, les échos de cette guerre parvenaient ainsi à la prison du soudan.

En lisant les pages du Liber Ostensor relatives à l'histoire récente de la couronne d'Aragon, l'on s'aperçoit, en effet, que Jean de Roquetaillade dispose d'un bon réseau d'information. C'est d'autant plus vrai qu'il affirme ne mentionner dans son ouvrage que des fragments de ses Chroniques $^{23}$. Ce manuscrit historique aujourd'hui disparu est sans doute une sorte de carnet de notes où il marque, au jour le jour, les faits dont il prend connaissance. Ces renseignements ne proviennent que rarement de

21 Bella campalia fient in partibus Ytalis et tam maris litora quam terra cadaveribus putrefient, L.O. fo $65 \mathrm{r}^{\circ}$.

${ }_{22}$ Dicit tam maris litora in bellis navalibus Mediterranei maris regis Aragonum contra Januenses et Januensibus contra Venetos inter quos duo horribilia bella sunt in mari hiis annis comissa, que in Cronicis meis satis expresse descripsi, ac in bellis regis Aragonie contra ei rebellantes in Sardinia, ubi in litore maris ante Salguerium in obsidione ex corruptione aeris, secundum communem extimationem, perdidit rex circa XXVIII milia personarum, L.O. fo $65 \mathrm{r}^{\circ}$.

${ }^{23} \mathrm{Cf}$. la note ci-dessus. 
sources écrites - seul le Speculum historiale de Vincent de Beauvais est cité parmi ses documents historiques -, mais bien plutôt de conversations avec des membres de la curie. Roquetaillade les a de même obtenus dans les couvents franciscains où il a séjourné : l'ordre des mineurs est bien implanté en Catalogne et, de Tarragone à Aurillac, ses maisons apparaissent comme des relais remarquables dans la transmission des nouvelles. Ces informations fournissent aux méditations du «pauvre emprisonné » une précieuse matière première qu'il transforme en prodromes de l'avènement de la fin des temps. Au creuset d'une analyse prophétique, ces événements sont souvent déformés, comme le prouvent des flottements chronologiques pas toujours très innocents ${ }^{24}$. La mémoire de Jean de Roquetaillade est sélective: ce sont la guerre et la famine, cavaliers de l'Apocalypse, qui retiennent son attention. Les campagnes militaires et leur triste cortège sont bien représentés sous le règne de Pierre IV qui est aussi impérialiste que centraliste. C'est pourquoi l'attention de notre prophète de malheurs est braquée sur ses terres, où il trouve d'ailleurs d'autres centres d'intérêt.

\section{UNE LECTURE PRO-FRANÇAISE DES JOACHIMITES CATALANS}

André Vauchez a démontré que Jean de Roquetaillade n'est pas, en matière de pauvreté, un spirituel acharné et que, sans suivre pour autant les conventuels, il inscrit plutôt son discours dans le sillage des observants $^{25}$. En revanche, quand il parle politique, il apparaît profondément attaché au joachimisme, y compris dans ce que les spirituels ont pu apporter à ce courant.

Depuis au moins 1282, date où le soulèvement des Vêpres avait donné la Sicile à la maison d'Aragon, joachimisme et spiritualisme excrcent une forte influence chez les franciscains catalans. Frédéric III (1296-1337) fait de Palerme un refuge sûr pour les spirituels en déroute comme Ubertin de Casale et ses disciples toscans qu'il accueille en 131226; ce monarque prend souvent conseil d'Arnaud de Villeneuve et de Raymond Lulle qui

${ }^{24} \mathrm{Au}$ cours de son exposé du 22 avril 1988 au séminaire de l'U.A. 1011, C. Beaune a également démontré comment Jean de Roquetaillade faussait la généalogie des rois de France pour attribuer aux Valois des droits sur l'héritage des Capétiens qu'il déniait arbitrairement au roi d'Angleterre.

${ }^{25}$ Séminaire du 29 janvier 1988.

26 J. M. POU Y MARTI, Visionarios, beguinos y fraticelos catalanes, Vich, 1930, p. $102-110$. 
lui proposent un programme imbu de spiritualisme pour réformer son royaume et évangéliser Tunis ${ }^{27}$. À l'orée du XIVe siècle, la Sicile, mais aussi les Baléares, Montpellier et la Catalogne, sont fréquentés par ces personnages, véritables maîtres à penser de Jean de Roquetaillade.

\section{Deux modèles catalans}

Les écrits du valencien Arnaud de Villeneuve (c. 1238/40-1311) ont considérablement marqué le Liber Ostensor ainsi que les autres ouvrages de Jean de Roquetaillade. Arnaud réalise dans sa jeunesse des études de médecine à Montpellier : dans cette ville, il rencontre le dominicain Raymond Marti qui l'initie à l'hébreu et à l'arabe; c'est alors qu'il a dû acquérir ses connaissances alchimiques et cabalistiques. Il entre par la suite à la cour des rois d'Aragon dont il devient le médecin et le protégé : Pierre III (1276-1285) et ses descendants - Alphonse III (1285-1291) et Jacques II (1291-1327) - profitent de son savoir médical et de ses conseils. En 1298, il voyage à Paris où l'université condamne son œuvre dont l'hostilité à la scolastique est un trait qui ne va pas sans déplaire à l'officialité de cette ville; emprisonné, il ne doit sa liberté qu'à une démarche du vicomte de Narbonne. Arnaud passe ensuite quelques mois auprès de Boniface VIII qui apprécie chez lui autant le médecin qu'il ne prend pas au sérieux le philosophe. En 1304, il séjourne à Marseille. Puis, il est reçu aux cours de Sicile et de Naples et intervient dans la réconciliation entre Frédéric III et

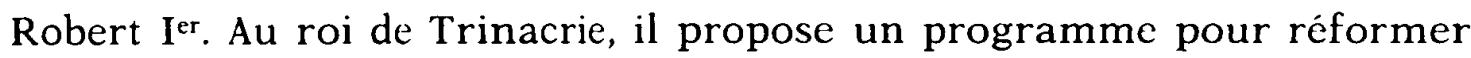
le royaume, axé sur les thèmes spirituels de pauvreté, mépris du monde et charité : Frédéric III s'en fait l'écho comme il ressort des statuts qu'il édicte aussitôt pour la Sicile; entre 1306 et 1309, Jacques II d'Aragon lui demande de mettre sur pied un projet de croisade. Grâce à la protection de ces monarques il échappe à l'inquisition jusqu'à sa mort, survenue en 1311 : c'est à titre posthume que ses écrits sont condamnés en novembre 1316 par le prévôt de Tarragone ${ }^{28}$. Au plus fort de la querelle de la pauvreté, l'œuvre d'Arnaud, aux lisières de l'orthodoxie et l'hétérodoxie, inquiète la hiérarchie.

La pensée d'Arnaud de Villeneuve est suspecte dans ce qu'elle cm-

27 M. MEnÉndez y Pelayo, Historia de los heterodoxos españoles, t. III, Madrid, 1917, p. XLIX-CXV.

${ }^{28}$ Cf. notamment Pou, Visionarios..., p. 34-110. Ses œuvres se trouvent dans M. Menéndez y Pelayo, loc. cit. ainsi que dans H. FinKe, Aus den Tagen Bonifaz VIII, dans Funde und Forschungen, Munster, 1902, p. CXVII-CCXI. 
prunte aux spirituels. Le médecin valencien admire sincèrement Pierre Jean-Olieu et les béguins de Narbonne auxquels il consacre un opuscule: Informatio beguinorum vel lectio Narbone. Il est, d'ailleurs, un joachimite fervent et s'adonne aux prophéties de type eschatologique. Il développe particulièrement les idées de Joachim de Flore dans De semine scriptarum, un commentaire sur l'Apocalypse. Une obsession toute joachimite envers l'Antéchrist transparaît dans De adventu Antichristi et fine mundi, où il préconise la pauvreté absolue pour se débarrasser de la Bête dont les mauvais prêtres préparent le terrain. Jean de Roquetaillade semble avoir emprunté à Arnaud aussi bien ses éloges pour Pierre Jean-Olieu que sa fixation sur l'imminence de la fin du monde. Quand il apparaît dans le Liber Ostensor, Arnaud de Villeneuve est Magister ${ }^{29}$.

C'est sans doute à travers son œuvre que Jean de Roquetaillade prit connaissance de l'oracle du pseudo-Cyrille cher à Arnaud. Les citations de cette prophétie émaillent le Liber Ostensor; le premier en date des ouvrages connus de Roquetaillade, écrit entre 1345 et 1349 , en est un commentaire en règle ${ }^{30}$. Cet oracle apocryphe connut une large diffusion dans les terres de la confédération catalano-aragonaise où il circule de façon considérable dans les années 1280-1300. Peut-être Arnaud de Villeneuve en était-il l'auteur plutôt que le simple glossateur? En tout état de cause, sa plus vieille version connue se trouve dans la première partie du De adventu Antichristi et fine mundi. Cet ouvrage est la glose des obscures prophéties que Cyrille, ermite du Mont-Carmel, auraient reçues sur deux tables d'argent des mains d'un ange; Arnaud en aurait pris connaissance par une Epistola ad Cyrilum attribuée à Joachim, correspondant du visionnaire ${ }^{31}$. D'après les sources inquisitoriales, les spirituels catalans tenaient ce livre pour révélé; la sentence de 1316 jette l'anathème sur l'affirmation selon laquelle l'oracle de Cyrille est plus précieux que les saintes Écritures. C'est bien de la Bible de l'âge du Saint Esprit dont il est ici question ${ }^{32}$.

D'après Nicolas Eymérich, inquisiteur dominicain, certains spirituels voyaient chez Raymond Lulle (c. 1232-1315), le célèbre philosophe majorquin de sensibilité franciscaine ${ }^{33}$, le Messie du dernier âge du trithéisme

29 L.O. fo $16 \mathrm{v}^{\circ}$ et $146 \mathrm{v}^{\circ}$.

30 Bignami-Odier, Etudes. ., p. 66-67.

31 M. REEves, The Influence of Prophecy in the Later Middle Ages. A Study in Joachimism, Oxford, 1969, p. 57-58.

32 M. Menéndez y Pelayo, loc. cit.

${ }^{33}$ L'ouvrage le plus récent en langue française sur cet auteur reste Raymond Lulle et le Pays d'Oc, (Cahiers de Fanjeaux, XXII), Toulouse, 1987. 
historique. Ce personnage exerce une forte fascination chez Jean de Roquetaillade qui lui consacre un éloge dithyrambique. Dans le douzième traité du Liber Ostensor, il est évoqué en comparaison avec Minerve, l'inventrice des sciences et de l'art. Voici la traduction que L. Boisset donne de ce passage: "Or, au temps de Célestin $V$ et au-delà même du règne entier de Philippe le Bel, le 'roi des couronnés' dont on a parlé, fleurissait à Paris un philosophe barbu - c'était son surnom - du nom de Raymond Lulle, de Majorque. Bien qu'il fût laìc et pour ainsi dire sans culture, il parvint à un tel sommet de la philosophie qu'il composa trente-cinq livres aptes à faire découvrir toutes les sciences et résoudre tous les problèmes, livres si stupéfiants que l'esprit humain ne le saurait croire, s'il ne les voyait par expérience et par intelligence et il en a composé plusieurs autres, en tout deux cents environ. La manière cependant de les utiliser n'est connue que d'une élite très restreinte, si bien que ses ouvrages dorment presque inutiles du fait de la faiblesse de l'intelligence des hommes. Il est ainsi possible, d'une certaine façon, que Raymond lui-même ait été la dite Minerve ${ }^{34}$. Aussi bien le caractère presque ésotérique des écrits de Lulle, réservés à un groupe restreint d'initiés, que la dimension eschatologique de ce personnage, prédit par les prophéties, transparaît nettement dans ce passage. L'admiration que Roquetaillade éprouve à son égard témoigne une fois de plus de ses contacts avec les béguins catalans.

\section{Un discours anti-aragonais}

Même si les inspirateurs de son œuvre travaillent pour la maison d'Aragon, Jean de Roquetaillade n'éprouve que peu de sympathie à l'égard des rois qui en sont issus. Qui pis est, ces derniers, nés dans l'engeance de Frédéric II, éveillent sa méfiance. Au cinquième traité, par exemple, il loue les trois dynasties françaises qui combattent, au service de l'Église, les tyrans de l'Empire germanique en France, les Tartares en Hongrie et «les fils du persécuteur Frédéric II» dans les Pouilles ${ }^{35}$. Il fait ainsi allusion aux luttes qui opposent les descendants de Charles d'Anjou, rois de Naples, aux Catalans installés en Sicile où ils reprennent le flambeau gibelin au détriment de la papauté.

C'est également aux liens entre l'Empire et la Catalogne qu'il s'en

34 L. BoIsset, Un témoignage sur Lulle en 1356: Jean de Roquetaillade, dans Raymond. .., cité note ci-dessus, p. 70-74.

35 L.O. fo $35 v^{\circ}-36 r^{\circ}$. 
prend tandis qu'il commente un de ces oracles attribués à Merlin qui connaissaient un si grand succès dans la Catalogne de la fin du XIII siècle ${ }^{36}$. Voici la traduction de cette prophétie qui aurait été répertoriée en 1285 dans le royaume d'Aragon, au retour de la «croisade» menée par Philippe le Hardi contre Pierre III ${ }^{37}$ : «Les lions parthes (ou les léopards?) essayeront d'anéantir le lis dans la jeunesse. Les petits du lion viendront et dévoreront les fleurs de lis. Un aigle ardent surgira de la terre portant un liquide virginal dans son ventre dont sera mouillé la poitrine du plus grand " ${ }^{38}$. C'est ainsi qu'il interprète le dernier membre de cette prophétie : «De la terre, c'est-à-dire des royaumes et des terres soumises à Pierre, alors roi des Aragons, et de sa race; surgira un aigle ardent, c'est-à-dire un futur empereur romain très furieux et rempli d'une colère incroyable; portant un liquide virginal dans son ventre, c'est-à-dire qu'il aura le désir de verser le sang des clercs parce que l'on entend par liquide virginal le sang des clercs qui sera versé; de ce sang du plus grand, c'est-à-dire du Souverain Pontife, sera mouillé la poitrine, à prendre au sens littéral, sans glose. J'entends par cet aigle l'empereur de l'A pocalypse, chapitre XIII, qui monte de la mer. Quand on dit qu'il sortira de la terre, il veut dire de la terre humide (jeu de mots avec humus), de l'île de la mer, comme l'affirme le texte de l'Apocalypse. Je crois comme beaucoup que cet aigle monte des humeurs du roi Pierre d'Aragon et de sa race ${ }^{39}$. Il poursuit son raisonnement quelques folios plus tard: commentant une pensée de Cyrille, il conclut que le plus grand fléau de l'Église proviendra de la postérité de Frédéric II et Pierre III ${ }^{40}$. Au XIVe siècle, les Barcelonais parviennent à s'emparer des attributs des Hohenstaufen en matière de messianisme eschatologique.

${ }^{36}$ Michi videtur quod hec prophecia valde sapiat stilum Merlini, L.O. fo $143 \mathrm{v}^{\circ}$. Cf. P. Bohigas, Profecies de Merli. Altres profecies contingudes en manuscrits catalans, dans Butlleti de la Biblioteca de Catalunya, 1928-1932, p. 253-279.

37 Aliud oraculum repertum in regno Aragonie post mortem Philippi regis Francorum qui obiit Perpiniani, rediens cum exercitu suo de Girona quam ceperat contra Petrum Aragonie regem, L.O. fo $143 \mathrm{v}^{\circ}$, Remarquons au passage que Jean de Roquetaillade embellit encore l'histoire au profit du roi de France qui ne prit jamais Gérone : au contraire, la résistance de cette ville l'obligea à rebrousser chemin vers le Roussillon.

${ }^{38}$ Leoni partiti lilium in juventute adnichilare temptabunt. Venient catuli leonis et flores liliorum devorabunt. De humo exibit aquila ardens in ventre liquorem virginalem portans, de quo maximi pectus humectabitur, L.O. fo $143 \mathrm{v}^{\circ}$.

39 L.O. fo $144 \mathrm{r}^{\circ}$.

40 De posteritate Frederici et Petri regis Aragonum maximum contra Ecclesiam egredietur flagellum, L.O. fo $147 \mathrm{r}^{\circ}$. 
Toujours dans le douzième traité, Jean de Roquetaillade confirme sa connaissance de la maison de Sicile d'Aragon dont il est capable de retracer la filiation sans faille: "Avant le début de cette année (1356) mourut le jeune Louis, roi de Trinacrie (1342-1355), et son frère le jeune Frédéric (1355-1377) commença à régner à sa place. Ce dernier est, au pied de la lettre, de la race de Frédéric II (1197-1250) et de Pierre (1276-1285), roi des Aragons. Parce que Frédéric II, pseudo-empereur, engendra Manfred (1254-1266), qui engendra Constance († 1302), reine d'Aragon, de laquelle le roi Pierre engendra Frédéric (1296-1337), roi de Trinacrie, qui engendra le roi Pierre (1337-1342), qui engendra Louis et son frère Frédéric qui règne à ce jour ${ }^{41}$. En apparence, Jean de Roquetaillade tient le plus anti-sicilien des discours: c'est par les Catalans, descendants du faux empereur de Sicile, que le malheur s'abattra sur l'Église.

Seulement en apparence: le plus surprenant est que l'accusation d'après laquelle l'Antéchrist surgira de la maison d'Aragon est empruntée à Arnaud de Villeneuve, le fidèle conseiller des cours de Barcelone et de Palerme. Roquetaillade cite son commentaire sur Cyrille où le médecin valencien affirme que la bête aquiline, persécutrice de l'Église, est aragonaise; cela - poursuit-il - doit être mis en parallèle avec ses origines frédériciennes, chères à Joachim ${ }^{42}$; il se réfère sans doute à l'apocryphe attribué à l'abbé calabrais - le Super Hieremiam -, rédigé au milieu du XIII ${ }^{\mathrm{e}}$ siècle dans le Midi de l'Italie, qui présente Frédéric II en Antéchrist et croit à l'imminence d'une coalition entre l'Empire romain-germanique et l'Islam ${ }^{43}$. Le provençal Hugues de Digne, que Salimbene appelle le "grand joachimite», accordait une grande importance à cet opuscule, très hostile à Frédéric $\mathrm{II}^{44}$; pourtant, en 1243 , il jouait bel et bien la carte du Hohenstaufen en demandant à l'évêque de Marseille de lever l'interdit sur la commune de cette ville partisane de Frédéric II $^{45}$. Ici une récupération impériale de ces oracles n'est pas exclue.

Quelques décennies plus tard, leur exploitation dans le sens d'une propagande favorable aux Aragonais était d'autant plus plausible que le

41 L.O. fo $146 \mathrm{v}^{\circ}$.

42 Magister Arnaldus de Villanova super Cyrillum dicit eam futuram de Aragonia et Joachim expresse tenet quod erit de semine Frederici secundi, L.O. fo $16 \mathrm{v}^{\circ}$.

43 REEVES, The Influence..., p. 306.

44 ReEves, The Influence..., p. 166. J. Paul, Hugues de Digne, dans Cahiers de Fanjeaux, t. X, p. 79-96.

45 V.-L. Bourrilly, Essai sur l'histoire politique de la commune de Marseille des origines à la victoire de Charles d'Anjou (1264), Aix-en-Provence, 1925, pièce justificative 35 (18-V-1243). 
long combat qu'il menaient contre l'islam pouvait faire ressortir un aspect positif de leur action : ils détournaient alors à leur profit les prophéties relatives à cet empereur qui devrait étendre sa domination jusqu'en Terre sainte au détriment des musulmans pour établir son trône à Jérusalem. La familiarité de Jean de Roquetaillade à l'égard de ces thèmes ressort particulièrement dans le cinquième traité du Liber Ostensor où il soutient l'existence de deux Antéchrists, l'un oriental et l'autre occidental. L'Oriental, présenté sous les traits de la secte de Mahomet, sera écrasé par l'Occidental, qui doit être plutôt le roi d'Aragon que celui d'Angleterre $^{46}$. Fort probablement en dépit des intentions premières du prophète auvergnat, les Catalans sont ainsi exaltés.

Certes, ces prophéties pouvaient être utilisées de façon subversive pour mettre en question la domination de la maison de Barcelone qui incarnait, malgré tout, la bête de l'Apocalypse. Néanmoins, dans des terres où son pouvoir était solidement établi et où les mouvements contestataires à nature eschatologique n'étaient pas à craindre, elles servaient plutôt ses intérêts, accordant à sa royauté une dimension messianique. L'Antéchrist est ambivalent dans ce qu'il ressemble au Christ, que d'ailleurs il précède; même si elle prépare sa chute irréparable, son hypocrisie le rend pareil à lui, du moins dans les apparences ${ }^{47}$. Il est l'agent de la Providence et l'exécuteur des châtiments nécessaires. Ce rôle le rend beaucoup plus proche de l'ange exterminateur que de Satan. Il provoque un sentiment de fascination qui ressemble plus à la terreur sacrée qu'à la haine.

Jean de Roquetaillade n'est qu'en partie héritier de cette tradition gibeline. Il ne reprend le point de vue des visionnaires catalans que dans les quelques passages que nous venons de présenter. Dans ces occasions, où il cite in extenso et commente à profusion les joachimites du royaume d'Aragon, il se fait l'écho de la mission messianique des héritiers de Constance de Hohenstaufen. Cette race d'où surgira l'Antéchrist éveille autant chez lui la méfiance que la crainte révérencielle; les écrits de Roquetaillade servent alors les intérêts de la couronne d'Aragon et connaitront ainsi un grand succès outre-Pyrénées. Toutefois, le Liber Ostensor est d'un tel éclectisme que son auteur, prisonnier de la diversité de ses multiples références, a du mal à suivre une démarche cohérente : c'est sans scrupules qu'au fil du texte il reniera des thèses soutenues avec ardeur quelques

46 L.O. fo 36-37.

47 A. Milhou, Colón y su mentalidad mesiánica en el ambiente franciscanista español, Valladolid, 1983, p. 135. 
folios auparavant. Dans ce sens, ce qu'il écrit au sujet des princes de la dynastie barcelonaise est bien plus le fruit d'un emprunt de circonstances que d'une position personnelle longuement mûrie.

C'est ailleurs qu'il dévoile le véritable fonds de sa pensée. Pour Jean de Roquetaillade, les maisons d'Aragon et de Souabe représentent surtout les ennemis traditionnels des rois de France et de leurs parents qui tiennent dans son discours le haut du pavé. Ces derniers font preuve d'un attachement sans bornes à l'égard de la papauté que bafouent précisément Frédéric II et ses descendants: «les Francs surtout de la Gaule et des Pouilles ont été unis depuis des temps immémoriaux dans leur amour immense envers les recteurs de l'Église universelle et romaine ${ }^{48}$. Cet amour est réciproque; il trouve sa contrepartie dans les multiples marques d'affection dont les Souverains Pontifes ont toujours fait preuve envers la maison de France: "L'Église romaine aime beaucoup la fleur de lis, c'est-à-dire l'empereur des francs, l'Empire franc et les royaumes qui sont issus de cet Empire et de la dynastie royale de France ${ }^{49}$. Jean de Roquetaillade exploite ainsi les thèmes de l'alliance et de l'amour entre la France et l'Église: les rois à la fleur de lis sont devenus le bras du pape, d'après un thème très usité dans l'historiographie officielle de la maison de France ${ }^{50}$. Il est, en outre, conscient que ces liens se sont affermis considérablement avec le départ de la papauté en Avignon. Dans son commentaire d'Isaie 30, il affirme que la France est le type de l'Égypte: de même que cette terre avait jadis accueilli le peuple élu dans sa détresse, la France reçoit aujourd'hui l'Église persécutée; ce n'est pas dans ce passage que Roquetaillade oserait développer le thème d'Avignon comme nouvelle Babylone qu'il n'hésite pas à traiter ailleurs. C'est enfin de la royauté française, des descendants de ce même Pépin qui avait le premier dans sa maison reçu le sacre des mains du pape, que devra surgir le réparateur franciscain qui écrasera l'Antéchrist. En somme, dans la pensée eschatologique de Jean de Roquetaillade, la monarchie française détient le plus beau rôle.

Le problème des origines de cette utilisation fort originale du joachimisme pour exalter la maison de France reste posé. Peut-être Jean de Roquetaillade s'inscrit-il dans une tradition pour laquelle les spirituels

${ }^{48}$ Franci maxime Gallie et Apulie conjuncti a priscis temporibus amore nimio rectoribus Ecclesie generalis romane, L.O. fo $35 \mathrm{r}^{\circ}$.

49 Romana ecclesia multum diligat florem lilii, scilicet imperatorem Francorum et Imperium francum ac regna que ab illo Imperio de genere ragale Francie processerunt, L.O. fo $34 \mathrm{v}^{\circ}$.

so Exposé de C. Beaune à l'U.A. 1011 le 22 avril 1988. 
languedociens auraient jeté les bases? Le nom de Pierre Jean-Olieu, dont notre prophète défend les positions en matière de pauvreté, vient aussitôt à l'esprit. L'influence du béguin de Narbonne aurait-elle dépassé la plan strictement religieux pour empiéter dans le domaine du politique? En fait, dans l'état actuel des recherches, l'on ne peut pas affirmer que Pierre Jean-Olieu ait préconisé un rôle eschatologique pour la maison de France. Tout au plus a-t-il consolé les enfants de Charles II, comte angevin de Provence, dans leur captivité en Catalogne; mais la lettre qu'il leur écrit à cette occasion est loin d'être un manifeste joachimite ou un pamphlet en faveur de la maison de France ${ }^{51}$; qui plus est, Charles II s'opposa toujours à une rencontre entre ses fils et le béguin languedocien dont il se méfiait. Avec les précautions d'usage, nous pensons donc devoir conclure que la rencontre entre le joachimisme et la maison de France se fait pour la première fois dans l'œuvre de Jean de Roquetaillade.

L'attitude du franciscain auvergnat à l'égard des rois d'Aragon est, somme toute, double. D'une part, dans la plus pure tradition gibeline, ces derniers incarnent les qualités d'un Antéchrist occidental doté d'une mission messianique et exerçant une fascination certaine dans les esprits. De l'autre, dans le sillage des penseurs guelfes voire des spirituels languedociens, ils deviennent l'engeance de Lucifer par leur injuste hostilité envers la papauté et la maison de France que Jean de Roquetaillade tient dans une très haute estime. Cette seconde vision des Catalans, au demeurant fort négative, l'emporte dans la pensée de notre visionnaire qui n'est attaché à la maison d'Aragon que quand il suit de trop près les textes d'Arnaud de Villeneuve et des pseudo-prophètes au service des héritiers de Frédéric II. Dès lors, le changement de perspective vis-à-vis de ses mâ̂tres à penser, les béguins catalans, n'est que plus évident. Nous avons désormais affaire à une utilisation pro-française des oracles siciliens et aragonais à l'opposé de leur mission première J. Chiffoleau a pu ainsi parler, à juste titre, de Jean de Roquetaillade en tant que «prophète de transition $»^{52}$ : son œuvre révèle, en effet, un personnage très éloigné d'un franciscanisme primitif qui préconisait jadis la pauvreté absolue et qui succombait souvent à la tentation d'un engagement politique et social quelquefois ouvertement gibelin ${ }^{53}$. Ce courant, largement représenté

51 La traduction de cette lettre par H.-M. Vicaire se trouve dans Cahiers de Fanjeaux, t. X. Cf. R. MANSElli, La "Lectura super apocalipsim» di Pietro di Giovani Olivi. Ricerche sull'escatologismo medievale, Rome, 1955, p. 167-172.

52 Exposé au séminaire de l'U.A. 1011 du 8 janvier 1988.

53 Cf. A. VAUCHEZ, Une campagne de pacification en Lombardie autour de 1233, dans $M E F R, 78,1966$, p. 503-549 où les mendiants apparaissent comme "prédica- 
chez les mineurs catalans, n'apparaît plus guère dans le Liber Ostensor. Il n'empêche que, dès la fin du XIVe siècle, les ouvrages de Roquetaillade seront à leur tour exploités par la maison de Barcelone: il suffisait de faire disparaître le roi de France pour y puiser une propagande apte à redorer le blason des Aragonais. Les avatars des thèmes du joachimisme catalan et leur transformation successive témoignent, une fois de plus, de «la plasticité de la matière prophétique» chère à A. Milhou ${ }^{54}$.

\section{UNE PERCEPTION NÉGATIVE DE L'ALTÉRITÉ}

Loin de l'attiser, la chute de Jérusalem en 1197 commença à éteindre en Occident le feu de la Croisade : le doute sur le bien fondé de la guerre sainte traversa l'esprit des élites de la chrétienté latine; les critiques contre la conquête armée de la Terre sainte se multiplièrent ${ }^{55}$. C'est dans ce contexte que s'insère le message de François : une œuvre missionnaire destinée à convertir les infidèles était possible; le martyre en Orient, affronté courageusement pour l'évangélisation, était aussi admirable que la mort du croisé dans le combat. Le saint d'Assise prêcha de son exemple: à l'occasion de la quatrième croisade, il se rendit en Palestine où il tenta de convertir le sultan Malek al-Kamil par sa prédication ${ }^{56}$. Ses disciples devaient suivre ses pas, s'engageant corps et âme dans l'évangélisation de l'Orient : dès 1292 quelques franciscains résidaient déjà à Pékin, où un archevêque, Jean de Montecorvino, est attesté en $1308^{57}$.

Une mentalité différente à l'égard de l'islam, pétrie de curiosité voire de compréhension, ainsi que de la croisade, dont on met en doute le bien fondé, est corollaire de ce mouvement missionnaire. Nous verrons qu'elle se manifeste particulièrement dans les écrits de Raymond Lulle et, dans un moindre degré, chez Arnaud de Villeneuve, auxquels Jean de Roquetaillade avait consacré des éloges enflammés. Pourtant, un demi-siècle plus tard, notre franciscain semble étranger à cet esprit. Une comparai-

teurs, paciaires et législateurs» (p. 506) dans le cadre du mouvement de l'Alleluia, bien qu'ils adhèrent plus souvent au parti du pape qu'à celui de l'empereur. J. Chiffoleau, Les mendiants, le prince et l'hérésie à Marseille vers 1260, dans Provence historique, 1986, p. 3-19, sur le gibelinisme des mineurs provençaux.

54 Colón... p. 381.

55 E. SiberR Y, Criticism of Crusading, 1095-1274, Oxford-New York, 1985.

56 R. Manselli, Saint François d'Assise, Paris, 1980, p. 195-198.

57 J. Richard, La papauté et les missions d'Orient au Moyen Âge, XIII ${ }^{e}-X I V^{e}$ siècles, Rome, 1977, p. 144-166. 
son s'impose encore entre leurs œuvres, pour voir ce qui, en deux générations de franciscanisme, pouvait séparer dans ce domaine les spirituels de la cour d'Aragon de Jean de Roquetaillade.

\section{La mission chez Raymond Lulle et Arnaud de Villeneuve}

Raymond Lulle appartient au patriciat urbain de Majorque. Introduit dans la cour de Jacques $I^{\text {er }}$ dès son adolescence, il devient le sénéchal de table et le précepteur du jeune Jacques II (1276-1311), roi de Majorque. En 1257, il épouse une fille de la noblesse catalane, Blanca Picany, dont il se sépare lors de sa conversion survenue entre 1262 et 1265 . Il mène ensuite une vie itinérante d'après l'idéal de vie des franciscains dont il intègre le tiers ordre. Ses déplacements sont déterminés non seulement par sa quête intellectuelle, qui le mène jusqu'à Paris où il obtient une maîtrise ès arts en $1288^{58}$, mais aussi par son activité missionnaire. En 1276, à Miramar, un lieu écarté de l'île de Majorque, il fonde la première école de langues orientales en Occident; au concile de Vienne (1312), il obtient la promulgation du «canon des langues» qui prévoit la création de plusieurs chaires d'hébreu, arabe et chaldéen dans les États de la chrétienté latine; cette même année il rédige le Liber de participatione christianorum et sarracenorum au titre significatif. À plusieurs reprises il se rend en Ifriqiya : il est à Tunis en 1293; à Bougie en 1307 et encore à Tunis en 1315, où la légende veut qu'il serait mort lapidé.

Son attitude envers l'islam, qu'il connaît remarquablement bien, se fonde sur la tolérance et l'objectivité; l'évangélisation des musulmans préconise-t-il - doit plutôt s'enraciner dans l'argumentation que dans l'autorité. Raymond Lulle est pleinement conscient que la violence ne saurait justifier à elle seule les conversions. Dans son Libre de contemplació, il critique durement l'idée de croisade et propose une évangélisation qui rappelle celle du Christ et ses apôtres: "Seigneur glorieux, pieux, humble, doux, simple et délicieux, je vois partir beaucoup de chevaliers en Terre sainte d'Outremer qu'ils comptent conquérir par la force des armes. Or, ils s'épuisent sans être à la fin parvenus à leur but. Selon moi, Seigneur, la Terre sainte ne doit être conquise autrement que de la façon dont vous et vos apôtres l'avez conquise : avec amour, prières, versement de larmes et effusion de sang ${ }^{59}$. Autrement dit, il s'agit de reprendre les

58 J. N. Hillgarth, Ramon Lull and Lullism in fourteenth-century France, Oxford, 1971.

59 Éd. Biblioteca selecta, Barcelone, 1957, CXII, n. 10. Traduction de l'auteur. 
lieux saints "per predicació mills que per força d'armes »: que les princes et les chevaliers fassent preuve d'amour vis-à-vis des infidèles, qu'ils deviennent martyrs pour le Christ, et les sarrazins embrasseront la foi ${ }^{\mathbf{0}}$. On comprend aisément ce qu'à l'orée du XIVe siècle un tel message pouvait avoir de révolutionnaire.

Arnaud de Villeneuve suit sur ce point son ami de la cour de Sicile. Il regrette, en effet, l'absence de missions en terre d'islam. Dans son interprétation des rêves de Jacques II d'Aragon et de Frédéric III de Sicile, ses protecteurs, il s'en prend de façon virulente au Saint-Siège: "Nous voyons ainsi qu'il ne cesse de prêter main-forte à ceux qui tuent les schismatiques, mais qu'il ne sollicite pas d'aide pour les ramener (à l'Église) : il ne s'occupe d'ailleurs guère de convertir les sarrazins "61. Il déconseille de même formellement à ces deux monarques de forcer les captifs musulmans au baptême : il vaut mieux les traiter chrétiennement et la conversion s'ensuivra. La secte de Mahomet - affirme-t-il - doit certainement disparaître à la fin des temps, mais dans un contexte d'adhésion massive au christianisme plutôt que de destruction ${ }^{62}$. Ici encore la mission l'emporte sur la guerre sainte:

Il faudrait toutefois apporter une petite nuance à cette adhésion sans conteste à la prédication pacifique. Ni Raymond Lulle ni Arnaud de Villeneuve n'excluent pas tout à fait la possibilité d'une croisade. Le philosophe majorquin en est partisan dans son Liber de Fine (1305) pour reprendre Grenade ${ }^{63}$; en 1309 , le médecin valencien prépara même, à la demande de Jacques II et de Frédéric III, un projet d'expédition contre ce royaume ${ }^{64}$. Mais ici nous restons encore dans le cadre de la «reconquista» de la péninsule Ibérique et même si l'idée de croisade réapparaît dans certains de leurs écrits, la mission est en fin de compte la solution prédominante.

Cette ouverture à l'islam persiste tout au long du XIVe siècle dans la confédération catalano-aragonaise. En 1381, Pierre IV demanda une tra-

- Ibidem, n. 11 et 12.

61 Item videmus quod pro scimaticiis occidendis non cessat prestare favorem, sed pro eis reducendis non videmus eam sollicitari : pro Sarracenis autem convertendis minime curat, MenÉndez y Pelayo, Historia. .., p. LIII.

62 Ibidem, p. LXXXVII-LXXXVIII. 365.

${ }^{63}$ A. Llinares, Ramon Lulle, philosophe de l'action, Grenoble, 1963, p. 348-

64 Menéndez y Pelayo, Historia... p. LXXIII. L'antisémitisme d'Arnaud, qui se scandalise au sujet des chrétiens qui se font soigner par des médecins juifs, semble répondre d'abord à un réflexe corporatiste. 
duction du Coran aux intellectuels de sa cour. Le cas d'Anselme Turmeda, l'auteur de la célèbre Disputa de l'ase (1417), est fort significatif de cette attitude : né à Majorque, il devient franciscain au couvent de Montblanc en 1375; après avoir étudié à Bologne et Paris, il se rend en Sicile et s'embarque, en 1385, pour Tunis; dans cette ville, il entre dans l'entourage du sultan, devient musulman et se marie. Ni son état de renégat ni la libre pensée qui transparaît dans son ouvre ne nuisent en rien à ses rapports avec les rois d'Aragon qui lui accordent, à plusieurs reprises, des saufconduits pour circuler librement sur leurs terres ${ }^{65}$. La liberté d'esprit qui règne dans le franciscanisme catalan du XIVe siècle est, pour le moins, surprenante.

\section{La croisade chez Jean de Roquetaillade ${ }^{66}$}

L'œuvre de Jean de Roquetaillade se trouve aux antipodes de cette conception si souple des rapports avec l'islam. Dans son système eschatologique, la destruction des sarrazins est un élément central; elle est la seconde phase d'une fin du monde qui se fait en trois temps: pacification de la terre, suppression des musulmans et expansion universelle de l'Église; le tout aura été précédé par l'avènement du réparateur, l'arrivée des deux Antéchrists et les tribulations de la France ${ }^{67}$. Cette vision apocalyptique relègue les musulmans à une bien humiliante position: ils seront inexorablement anéantis à l'instar de l'Antéchrist oriental qui les personnifie. Cette disparition de l'islam et ses partisans est ardemment désirée par Roquetaillade qui les rejette du côté de la peur et du noir : "la secte de Mahomet qui a toujours été la crainte du peuple chrétien, les ténèbres de la loi du Christ et son obscurcissement ${ }^{68}$. Contrairement à Raymond Lulle, l'incompréhension de l'autre est totale chez Jean de Roquetaillade.

C'est au sujet de la prophétie du vieil ange barbu du cinquième traité que le franciscain auvergnat exprime avec plus de force son point de vue. La phrase «.A. Cedar sera renversé par un .A. roi avec un autre», contenue dans cet oracle, retient son attention. Roquetaillade est convaincu que cet .A. Cedar est l'Antéchrist oriental : «À mon avis, ce .A. Cedar sera

65 PoY y MARTI, Visionarios..., p. 446-482.

66 Nous n'approfondisson pas ce point qui se trouve largement développé dans la communication de L. Boisset sur Jean de Roquetaillade et l'Orient publiée dans ce même volume.

67 L.O. fo $33 \mathrm{r}^{\circ}$.

68 Secte Machometi que meror semper fuit populi christiani et tenebrositas legis Christi et obscuratio ejus, L.O. fo $36 v^{\circ}$. 
un roi sarrazin très puissant qui viendra à l'encontre du peuple chrétien avec un peuple infidèle infini en nombre ${ }^{69}$. Ce personnage qui vient $d u$ levant dirige une armée composée de deux myriades de myriades à en croire la révélation de la sixième trompette de l'Apocalypse au chapitre IX. Le terme mystérieux de «.A. Cedar» renvoie irrémédiablement aux sarrazins: Qédar est, d'une part, l'un des douze fils d'Ismaël, fils d'Agar, dont descendent les arabes (Gen 25, 13); d'autre part, «Cedar» veut dire peur et ténèbres, les attributs que l'on sait correspondre parfaitement à la secte de Mahomet. Quant à la lettre «.A.», elle pouvait avoir trait au roi qui détient Alméria ou l'Al-Gerb, le couchant ou Maroc ${ }^{70}$. Un autre élément de cette prophétie tendrait à corroborer l'incarnation de la religion musulmane dans la personne de l'Antéchrist oriental : «Mais une fois la dent agaréenne, longtemps pestilentielle et stridente, vaincue, dont la racine du nom est 2105 , la molaire sera récupérée ${ }^{71}$. Il est facile d'identifier cette dent d'Agar "pestilentielle et stridente» avec l'islam et cette allusion est d'autant plus claire que le chiffre 2105 renvoie au nom de Mahomet d'après le schéma suivant : $M(A) C(H O) M(E T) V(S)^{72}$. En somme, l'islam est un Antéchrist d'autant plus méprisable qu'il est battu dès le premier tour du tournoi apocalyptique, par la bête de l'Occident.

Outre ces deux personnages, un troisième héros de l'univers eschatologique de Roquetaillade combat les musulmans. Il s'agit du réparateur franciscain de la famille de rois de France qui accédera au pontificat. C'est véritablement le Messie du troisième âge. Voici les attributs que notre prophète lui accorde: «celui qui attaque le très puissant Antéchrist, celui qui frappe les hérétiques mamonites, celui qui défend l'Église universelle, celui qui console les pauvres évangéliques, celui qui convertit les juifs aveugles, marteau des sarrazins, celui qui réduit les schismatiques, celui qui dilate l'Église universelle jusqu'aux confins de la terre, celui qui opprime les tyrans » ${ }^{73}$. Ce n'est pas sans dégâts qu'il mettra de l'ordre; parmi ses victimes, les musulmans seront les plus châtiés, car il doit «tuer

69 L.O. fo $36 v^{\circ}$.

70 Rex autem Granate habet Almariam magnam civitatem in regno suo prope regnum Valencie et esset possibile quod esset unus istorum, aut rex Algarbii qui est Marrochiorum, L.O. fo 37.

71 Sed devicto Agarenico dente diu pestifero atque stridente cujus radicis nomen est 2105 , recuperabitur molaris, L.O. fo38ro.

72 Roquetaillade affectionne particulièrement ce système numérique qui lui fait trouver la bête de l'Apocalypse, dont le chiffre est 666, chez Louis de Trinacrie : LVD(O)VICV(S).

73 L.O. fo $17 v^{\circ}$. 
les mouches importunes, c'est-à-dire les sarrazins ${ }^{74}$. Les personnages de l'Ancien Testament qui le préfigurent ne sont précisément pas des partisans de la paix: «il est Samson qui dans la force de l'esprit de Dieu détruit les Philistéens, sarrazins impies »75. Ce réparateur, que Jean de Roquetaillade présente sous les traits d'un matamore, est paradoxalement issu de ce même ordre des mineurs dont l'esprit imprègne toute l'œuvre de Raymond Lulle et encourage les missions d'Orient. En une génération à peine, le franciscanisme a subi une bien curieuse transformation.

L'image de l'autre chez Jean de Roquetaillade est des plus négatives. Son discours à l'égard des musulmans est très péjoratif : aucun effort de compréhension de l'islam n'est fourni dans son œuvre ${ }^{76}$. Son système prophétique, sa croyance à l'imminence de la fin du monde, n'expliquent qu'en partie son point de vue : la disparition de la «secte de Mahomet» correspond certes à la purification de la terre qui précède la parousie, mais là où Raymond Lulle et Arnaud de Villeneuve parlaient de "conversion», Jean de Roquetaillade ne voit que «destruction». Cette rupture par rapport aux décennies précédentes répond surtout à un nouveau contexte politique. Alors que des luttes intestines ravagent plus que jamais la chrétienté latine, la papauté avignonnaise recherche des solutions aux conflits; elle joue un rôle diplomatique de premier plan; ses légats parcourent l'Occident et proposent de s'ériger en arbitres dans les guerres civiles ou interétatiques. C'est dans la curie pontificale, consciente de sa mission pacificatrice, que renaît ainsi l'idée de l'ennemi mythique face auquel les chrétiens oublieraient les rancœurs passés, unissant leurs efforts pour combattre l'islam. La croisade retrouve ainsi sa vocation première et devient exutoire d'une violence mal contenue en Occident. Nous avons vu combien Jean de Roquetaillade était perméable aux idées en vogue dans le palais des Papes : la nouvelle sensibilité, la perception négative de l'altérité, qui transparaît si clairement dans le Liber Ostensor, répond bien à ce revirement mental qui s'est opéré dans les bureaux de la curie.

En dépit de ses différences avec les franciscains d'outre-Pyrénées, l'œuvre de Jean de Roquetaillade connut un succès considérable en Catalogne parce qu'elle plongeait ses racines dans le vieux fonds joachimite.

74 L.O. fo $11 \mathrm{r}^{\circ}$.

75 L.O. fo $71 \mathrm{r}^{\circ}$.

76 Le seul passage du Liber Ostensor où Roquetaillade manifeste un certain respect pour les juifs et les sarrazins concerne l'exactitude de leurs analyses astronomiques, L.O. fo 21 . 
Peu de temps après sa mort, même peut-être de son vivant, ses livres sont connus dans les terres de la confédération catalano-aragonaise. L'inventaire des ouvrages de la bibliothèque de Ramon de Farrés, abbé de Ripoll entre 1362 et 1380, mentionne un Tractatus de paupertate y un libre fratris Johannes de Rupescissa, de paper et pergami ${ }^{77}$. L'infant Pierre d'Aragon (1305-1381), oncle paternel de Pierre IV - pour lequel il écrivit un Tractatus de vita, moribus et regimine principum (1355-1358) à la mode de Gilles de Rome $^{78}$-, est une figure clef du franciscanisme catalan : se fondant sur les opuscules de Roquetaillade, il prédit en 1365 de nombreuses victoires en Espagne pour son neveu ${ }^{79}$. L'œuvre de notre prophète marqua de même la pensée de Francesc Eiximenis (1327?-1409), mineur de Gérone ayant réalisé ses études à Toulouse, conseiller de la ville de Valence, devenu évêque d'Elne et patriarche de Jérusalem à titre honorifique à la fin de ses jours; nous conservons une lettre que lui adressa le roi Jean Ier (1387-1395) en décembre 1391 : à cette occasion, le monarque lui reprochait l'interprétation d'une prophétie de Jean de Roquetaillade et de Talleyrand de Périgord; cardinal d'Albano, dans le sens de la disparition de toutes les maisons royales à l'exception de la française pour l'année $1400^{80}$; dans le douzième livre du Chrestià, Eiximenis mentionne, en effet, l'oracle d'après lequel, à cette date, le pape transférerait son siège à Jérusalem où les juifs auraient massivement adhéré au christianisme: une période de paix et justice populaire serait alors instaurée sur terre et tous les pouvoirs cesseraient à l'exception de celui du roi de France; le tout s'arrêterait avec l'avènement de l'Antéchrist et la fin du monde ${ }^{81}$. Quelques décennies plus pard, le majorquin frère Joan Eximeno (c. 13601420), ancien étudiant de Toulouse et évêque de Malte, encourageait Jacques d'Urgel, prétendant catalan à la royauté aragonaise, à tenir bon contre le nouveau roi d'Aragon d'origine castillane élu à la suite du compromis de Caspe (1412); il lui prédisait des temps meilleurs à la suite de

77 Pou y Marti, Visionarios. .,, p. 291.

78 Éd. F. VAlls TaBerner, Literatura juridica, Barcelone, 1986, p. 273-298.

79 POU Y MARTi, loc. cit.

${ }^{80} E$ aço que's conten en la dita vostra letra que.l cardenal d'Albana e frare Johan de Rochasist havien scrit a nostre pare, a qui Deus perdo, com se devia seguir en aquest centenar que la monarchia se sperave a la casa d'Arago, vos responem que be ha un any en l'archiu nos trobam aç, P. BoHigas, Profecies catalanes dels segles $X I V$ et XV, dans Butlleti de la Biblioteca de Catalunya, 1920-1922, p. 24-49.

81 A. RuBió i Lluch, Documents per a la història de la cultura catalana mig-eval, t. I, Barcelone, 1908, nº 318. 
Jean de Roquetaillade dont l'infante était une lectrice assidue ${ }^{82}$. Un oracle, écrit en Catalogne entre 1407 et 1420, présentait un impossible dialogue, daté de façon anachronique de 1347, entre Arnaud de Villeneuve et Pierre IV au sujet d'une cuvre de Roquetaillade dont le roi d'Aragon aurait demandé la traduction ${ }^{83}$. Les exemples de l'utilisation de ses écrits sont donc nombreux outre-Pyrénées. Comme A. Milhou l'a remarquablement démontré, c'est à cette tradition prophétique des spirituels catalans, lecteurs assidus du franciscain auvergnat, qu'il faut par la suite rattacher l'idéologie messianique qui entoure la figure des rois catholiques et des premiers Habsbourg, promis à l'instauration d'un Empire universel; à l'opposé, ces oracles furent utilisés de façon subversive dans l'Espagne moderne par les porte-parole de bien de mouvements populaires comme les Germanies valenciennes ${ }^{84}$. Par le truchement des franciscains de la confédération catalano-aragonaise, l'œuvre de Jean de Roquetaillade était promise à une longue postérité.

DANS LE ROYAUME DE CASTILLE : PIERRE I ${ }^{\text {er }}$ (1350-1369), RÉINCARNATION DE NÉRON

Ce n'est pas sans un humour sans doute involontaire que Jean de Roquetaillade commence le huitième traité du Liber Ostensor. Il fait alors la glose d'un passage de la prophétie Vae mundo in centum annis aussi hermétique que prometteuse en commentaires: "Les toits des Romains seront détruits par les licornes. La rupture du pont et l'immersion de l'âne présenteront des signes de la ruine qui approche » ${ }^{85}$. Pour notre prophète ce présage s'est accompli devant les yeux ébahis de toute la curie romaine: "Alors que le Pape Clément VI (1342-1352), qui gouvernait le monde à l'époque, venait de finir complètement le pont d'Avi-

82 Pou y Marti, Visionarios. ., p. 291 et 432-439.

83 Timore ductus ne persecutionem paterer recursum habui et refugium prefatum regem illustrum qui cum legisset librum magistri Johannis de Rippa Cisa michi quod dictum librum declararem. . BoHIGas, Profecies catalanes dels. ., p. 40-42.

${ }^{84}$ Milhou, Colón..., p. 390.

85 Romanorum fastigia diruet unicornis et ipsi propriis furoribus vorabunt. Quibus fractura pontis et asini submertio prebebunt signa ruina apropinquantis, L.O. fo $57 \mathrm{r}^{\circ}$. 
gnon $^{86}(.$.$) , un arc s'effondra sur lequel se trouvait un chapelain, chan-$ tre du cardinal d'Ostie Bertrand de Pouget (1280-1351), que l'on appelait publiquement l'âne dans la curie, et il fut englouti par le Rhône avec l'arc et tout travail de recherche pour le retrouver s'avéra inutile ${ }^{87}$. Et Roquetaillade d'exposer quelques lignes plus bas la conclusion qui s'impose : «Il est donc clair, en raison de l'expérience du signe de la fracture du pont et de l'immersion de l'âne, faite l'année du Seigneur 1345, que nous avons ces ruines aux portes, ce que nul ne saurait nier ${ }^{88}$. Décidément, l'année 1345 a bon dos!

Écrite entre 1297 et 1301, la prophétie Vae mundo in centum annis est attribuée à Arnaud de Villeneuve et connaît un large succès dans le monde hispanique jusqu'au XVII ${ }^{\mathrm{e}}$ siècle $^{89}$. Jean de Roquetaillade y ćtait très familiarisé : il la cite déjà dans le Liber secretorum eventuum (13481349 ) et y consacre tout un opuscule intitulé De oneribus orbis (13541355) ${ }^{90}$. Le huitième traité du Liber Ostensor correspond en partie au commentaire du long extrait de cet oracle dont voici la traduction : «L'Espagne, nourrice de l'erreur mahométane, sera déchiquetée par une colère réciproque. Alors les royaumes se lèveront d'une façon plus impie les uns contre les autres. Et quand le poulain de la jument aura réalisé trois septennats, le feu dévorateur sera multiplié jusqu'à ce que la chauve-souris dévore les mouches d'Espagne et que, subjuguant l'Afrique et broyant la tête de la bête, elle reçoive la monarchie et humilie les habitants du Nil "91. La lecture que Jean de Roquetaillade nous livre de cette prophétie

86 En novembre 1339, le pont était encore inutilisable: Pierre IV qui se rendait en Avignon dut à cette date emprunter le bac entre Beaucaire et Tarascon, per tal com lo pont d'Avinyó era nadoncs trencat e passaven ab barca, Crónica de Pere III, éd. F. Soldevila, Les quatre grans cròniques, Barcelone, 1971, chap. 2, §37.

${ }_{87}$ Cum enim fecisset totum pontem Avinionis perfici per integrum Clemens papa sextus tunc mundo imperans (.. .) unus arcus pontis cecidit super quem erat in vertice unus capellanus, cantor cardinalis Hostiensis Bertrandi de Poieto, qui publice per totam romanam curiam asinus dicebatur, et cum arcu pontis ita a Rodano absortus est ut numquam quocumque investigationis labore valuerit inveniri, L.O. fo $57 \mathrm{v}^{\circ}$.

${ }^{88}$ Clarum est igitur per experienciam signi preexpositi de fractura pontis et asini submersione facta anno Domini M.CCC.XI.V quod prefatas ruinas in januis habemus et negari non potest, L.O. fo $58 \mathrm{r}^{\circ}$.

89 Pou y Marti, Visionarios..., p. 54-55 et Milhou, Colón..., p. 376.

90 Bignami-Odier, Etudes..., p. 113 et 130-139.

91 Yspania, nutrix machometice pravitatis, reciproca furia laniabitur. Nam invicem impius regna consurgent. Et cum pullus jumentalis tria septenaria compleverit, multiplicabitur, ignis vorans, donec vespertilio cinifes Ispanie devoret subiciensque 
est aussi bien empreinte de critique contre le passé ibérique que d'espoir au sujet de son futur. Le passé de ces terres d'impiété, rongées par l'islam, contraste avec son futur, porteur de l'espoir d'un roi écrasant les mahométans et accédant à la royauté universelle. Mais surtout le franciscain auvergnat est, une fois de plus, prisonnier de son temps : c'est le présent qu'il vit avec ses contraintes politiques qui conditionne tous ses choix historiographiques et idéologiques.

\section{UN PASSÉ HISTORIOGRAPHIQUE}

Selon Jean de Roquetaillade, le succès de la religion islamique dans l'Espagne «nourrice de l'erreur musulmane» a été rendu possible par le péché de la royauté wisigothique. Il porte, en effet, un regard très négatif sur ces goths qui envahirent l'Hispania romaine. C'est ainsi qu'il interprète la prophétie suivante de Merlin venue à la rescousse de sa glose du Vae mundo : «l'Espagnol, dont jadis il nous était dit qu'il dormait jusqu'à présent, le fils du roi des Attalons, après son heureux couronnement, se ceint avec le Seigneur (...). Si je me rappelle bien, quelques-uns de ces rois goths avaient pour nom Attila ou quelque chose de semblable, c'est pourquoi il était possible que Merlin les appelât Castillans, Espagnols ou Attalons. En plus, il est clair, grâce aux chroniques, qu'il y eut en Afrique un roi des goths ariens hérétiques appelé Attila qui poursuivit l'Église catholique de saint Augustin pour un temps et qui fit une foule innombrable de martyrs. Ces peuples occupèrent plus tard les Espagnes et il est possible que Merlin appelât Attalons les Espagnols de Castille, issus de ces peuples africains d'Attila » ${ }^{92}$. La royauté hérétique des wisigoths est donc composée par des princes de la race d'Attila, persécuteur de l'Église africaine. Son salut vint toutefois de la France : "Je crois me souvenir d'après Vin-

Africam et caput bestie conterens accipiat monarchiam et in posteris humiliet Nili habitatores, L.O. fo $58 \mathrm{r}^{\circ}$-vo.

92 Consurgit Ispanus qui olim nobis hactenus dormire dicebatur, filius regis Attalorum post felicem coronationem suam cum Domino se percingit (...). Et si vere recordor quidam eorum Attila vel simile nomen eciam habuerunt unde possibile fuit quod Merlinus Castellanos, Ispanos, Attalos ab illis regibus appellaret. Nam ex cronicis clare habetur in Africa fuisse regem Gothorum hereticorum arrianorum qui Attila dicebatur qui catolicam Ecclesiam sancti Agustini tempore persequtus est et innumerabilem multitudinem martirum interfecit. Et illi populi postmodum Ispanias occuparunt et est possibile quod Merlinus Ispanos Castelle ab illis populis africanis regis Atile Attalos appellaret, L.O. fo $58 \mathrm{v}^{\circ}$ et $59 \mathrm{v}^{\circ}$. 
cent [de Beauvais] - mais je l'avais lu de façon confuse - que, du temps où les goths occupèrent les Espagnes, quelques-uns de leurs rois se convertirent au Christ prenant des épouses de la race royale des francs, suivant le conseil desquelles les rois d'Espagne de cette époque abandonnèrent l'hérésie arienne ${ }^{93}$. Jean de Roquetaillade noircit encore le tableau des royaumes hispaniques pour mieux faire ressortir le rôle fort positif de la maison de la fleur de lis dans l'histoire de l'Église.

Cette vision aussi négative des wisigoths contraste fortement avec celle des Castillans, engagés dans la «reconquista», pour lesquels le royaume d'Isidore est, en quelque sorte, le mythe fondateur de leur peuple, une sorte de paradis perdu qu'il faut retrouver à tout prix, en chassant les musulmans de la péninsule. En revanche, le point de vue de Jean de Roquetaillade est, une fois de plus, de souche strictement française. Ce n'est pas hasard s'il cite le Speculum historiale de Vincent de Beauvais, le dominicain de l'entourage de saint Louis, dont l'œuvre connut une très large diffusion au bas moyen âge ${ }^{94}$. Or, cet ouvrage a été écrit au service du prince pour mettre en valeur les gestes de la maison de France. Quoiqu'il prétexte d'une mémoire défaillante, Jean de Roquetaillade connaît bien ce passage où Vincent de Beauvais rapporte la victoire de Clovis sur un Alaric refoulé outre-Pyrénées, bien que les historiens le veulent aujourd'hui tué à Vouillé (507); toujours d'après le récit du Speculum, de retour en Espagne, le roi wisigoth, arien convaincu, aurait maltraité son épouse Rhotilde, qui voulait rester fidèle à la religion catholique; cela provoqua la colère du frère de Rhotilde, Childebert, vraisemblablement le fils de Clovis, qui vint en Espagne et tua Alaric ${ }^{95}$. Alors qu'à la fin du XIVe siècle Clovis est canonisé en France ${ }^{96}$, les francs apparaissent dans l'imaginaire de Jean de Roquetaillade comme des champions de l'ortho-

${ }_{93}$ In Vincencio memini me sed confuse legisse quod, tempore quo Goti Ispanias occuparunt, reges eorum aliqui fuerunt conversi ad Christum accipientes uxores de genere regali Francorum ad quarum monitionem reges Ispani illius temporis arrianam heresim reliquerunt, L.O. fo $59 \mathrm{v}^{\circ}$.

94 Cf. W. J. Aerts, E. R. Smits et J. B. VoorbiJ, Vincent of Beauvais and Alexander the Great: Studies on the "Speculum maius» and its Translations into Medieval Vernaculars, Groningen (PB), 1986.

${ }^{95}$ Hunc tandem Clodoueus Rex Franciae signis divini auxilii animatus in bello congreditur eoque perempto quicquid Galliarum Wisigothi possidebant ad partem Francarum transtulit. Amalricus autem fugiens in Hispaniam 16 annis ibidem regnavit. Cumque Rhotildem uxorem suam indigne tractaret eo quod Arianae sectae secum inservire nollet, a Childeberto fratre Rhotildis in Hispania peremptus est, V. DE BEAU. vaIs, Speculum historiale, t. IV, Douai, 1624 livre 16, chapitre 13.

96 C. Beaune, Naissance de la nation France, Paris, 1985, p. 65. 
doxie face à des wisigoths ariens n'abandonnant l'hérésie que grâce au zèle de leurs épouses, descendantes de Clothilde.

Dans ce récit, Roquetaillade renoue avec une tradition française de méfiance à l'égard de la Castille identifiée ici à l'Hispania wisigothique. Elle remonte certes aux temps de l'arianisme, mais elle se prolonge plus tard à l'époque de la querelle adoptienne ou du refus du rite romain par l'Église de Tolède. Ces mozarabes, dont l'ardeur chrétienne végète dans un monde politique où les cadres sont islamiques, ne méritent que le mépris de la part des habitants du nord de l'Europe. La situation se renverse au $\mathrm{XI}^{e}$ siècle alors que l'esprit de croisade se répand dans la péninsule avec l'arrivée des guerriers français et des moines clunisiens qui les suivent. La «reconquista» reprend de plus belle et, du coup, la Castille et la France deviennent aux XII ${ }^{\mathrm{e}}$ et XIII ${ }^{\mathrm{e}}$ siècles des alliés inséparables. On oublie les vieux contentieux et on accorde aux descendants des wisigoths une place de choix parmi les nations chrétiennes: dans l'imaginaire des années 1300, la Castille est devenue un solide pilier de l'Église ${ }^{97}$. Or, en 1356, reprenant l'oriflamme de l'inimitié franco-wisigothique, Jean de Roquetaillade s'inscrit en faux par rapport à plus de deux siècles de représentations politiques. Pourtant, sur ce point encore, il demeure bel et bien typique de sa génération.

\section{UN PRÉSENT POLITIQUE}

En 1350, Pierre I er accède au trône de Castille : il est le seul fils légitime d'Alphonse XI (1312-1350), mort devant les rnurs de Gibraltar qu'il essaie de reprendre aux Nasrides de Grenade. Par contre, ses demi-frères, nés de l'union de Leonor de Guzmán et du roi défunt, sont nombreux. Pour éviter d'éventuelles contestations, il fait assassiner la concubine de son père et brise leur parti : c'est alors que Gil de Albornoz, archevêque de Tolède, est expulsé de Castille et rejoint la plus sûre curie avignonnaise.

Les conseillers du jeune monarque entrent ensuite en pourparlers avec Jean II pour obtenir la main d'une princesse de sa maison et entériner par son mariage avec Pierre $\mathbf{I}^{\text {er }}$ la vieille alliance franco-castillane. Blanche de Bourbon, nièce du roi de France, est finalement proposée au Castillan et Jean le Bon s'engage à lui verser une dot fort consistante de

97 Ces idées sont empruntées à deux conférences d'A. Rucquoi dont on attend avec impatience l'ouvrage sur l'imaginaire du pouvoir dans la Castille médiévale. 
trois cent mille florins d'or. Le 3 juin 1353, les noces sont célébrées à Valladolid. Mais Pierre I $^{\text {er }}$ quitte aussitôt sa jeune épouse pour rejoindre sa concubine, María Diaz de Padilla; il n'aura guère de mal à obtenir la déclaration de nullité de son mariage de la part des évêques de Salamanque et d'Avila; quelques mois plus tard, le dernier de ces prélats bénit sa nouvelle union avec Juana de Castro.

\section{PIERRE I' ET SA FAMILLE}
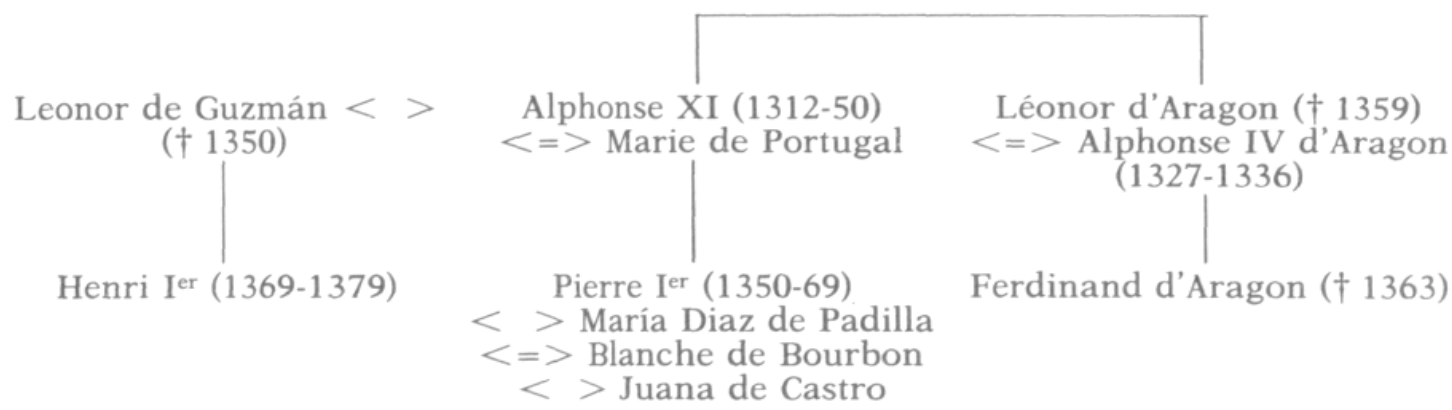

Entre temps, les efforts de centralisation du monarque provoquent un vaste mouvement de rejet au sein de la noblesse, toute-puissante en Castille, et des conseils des villes. Les mécontents se groupent autour de l'infant Ferdinand d'Aragon, retourné dans la terre de sa mère après l'échec des unions de Valence et Aragon, et autour d'Henri de Trastamare, fils aîné d'Alphonse XI et de Leonor de Guzmán. Les habitants de Tolède, où Blanche de Bourbon a été enfermée, se comptent parmi les premiers révoltés. Toutefois, en 1355, Pierre I $^{\text {er }}$ triomphe sur ses ennemis, prenant cette ville ainsi que Toro. Les rescapés de sa répression se réfugient en Catalogne, auprès de Pierre IV, et en Avignon. Dès lors, ils préparent leur retour en force en Castille ${ }^{98}$.

En été 1356, alors que la nouvelle vague d'exilés castillans arrive au palais du pape, Jean de Roquetaillade est en train de rédiger le Liber Ostensor. Son réseau d'information fonctionne bien et une fois de plus les événements d'outre-Pyrénées viennent à point nommé nourrir ses spéculations eschatologiques. «La destruction de toute l'Espagne accomplie

98 Pour l'histoire politique de la Castille sous le règne de Pierre I'r, cf. le chapitre de L. Suárez Fernández dans R. Menéndez Pidal, Historia de España, t. XIV Madrid, 1966; J. Catalina Garcia, Castilla y León durante los reinados de Pedro I, Enrique I, Juan I y Enrique III, Madrid, 1893; L. V. DIAZ MARTIN, Itinerario de Pedro I de Castilla. Estudio y Regesta, Valladolid, 1975. 
depuis trois ans par le stupide roi Pierre de Castille et ses frères bâtards ${ }^{99}$ est un décor de rêve pour son théâtre prophétique dans lequel trois acteurs tiennent le devant de la scène: le poulain de la jument, la colombe blanche et la chauve-souris.

Pierre Ier, "poulain de la jument»

C'est sans problème que Jean de Roquetaillade identifie «le poulain de la jument» annoncé par l'oracle Vae mundo in centum annis : il n'y a pas l'ombre d'un doute qu'il s'agit du roi de Castille. Il venait d'exposer les raisons de sa lumineuse découverte dans le De oneribus orbis: d'abord, les plus belles juments se trouvent dans le royaume de Castille; ensuite, les mœurs d'Alphonse XI qui entretenait une concubine sont fort chevalines; enfin, il en va de même avec Pierre Ier qui suit dans ce domaine les traces de son père défunt ${ }^{100}$. Ajoutons à cela la réalisation des trois septennats du poulain, moment clef du déclenchement de toutes les catastrophes à en croire l'oracle d'Arnaud de Villeneuve; cette prédiction s'accomplit en l'occurrence de façon admirable : "Ainsi, il saute aux yeux que le jeune poulain de la jument, Pierre, roi actuel de la Castille, fils de l'illustre roi Alphonse, vient d'avoir vingt-et-un ans. Et sous son règne les Espagnes sont dévorées par un si grand feu dans les guerres que beaucoup considèrent que la fin du monde est arrivée pour elles. Il mène ces guerres contre ses frères bâtards, contre les nobles et contre les communes qui soutiennent le parti de son épouse Blanche de Bourbon, reine de Castille, face à l'abominable prostituée qu'il a prise après avoir rejeté sa femme» ${ }^{101}$. La prophétie Vae mundo ne se trompait pas; le tout était d'être un esprit suffisamment éclairé pour savoir l'interpréter!

Personnage détestable, Pierre $\mathrm{I}^{\text {er }}$ est alter Nero, le grand persécuteur des chrétiens. Jean de Roquetaillade le dénigre dans une tirade comme on n'en trouve dans aucun de ses ouvrages: "Puisque le susdit Pierre de Castille, comme le veut la voix publique et sa renommée, est un buoc

99 Ac destructionem totius Ispanie factam a tribus annis citra per stultum regem Petrum Castelle et bastardos fratres ejus, L.O. fo $148 \mathrm{r}^{\circ}$.

100 Bignami-Odier, Études. .., p. 130-139.

101 Iam enim, oculata experiencia, inspicimus pullum jumentalem juvenum hodiernum regem Castelle Petrum, filium incliti regis Alphonsi, complevisse in etate annum XXIm et Ispanias tanto igne devorari sub eo in bellis que gerit contra fratres suos spurios et contra nobiles et communitates que sustinent partem uxoris ejus Blanche de Borbonio, regime Castelle, contra nephariam meretricem quam, abjecta uxore, recepit ut finis orbis estimetur a nonnullis Ispanis venisse, L.O. fo $58 \mathrm{v}^{\circ}$. 
puant la luxure, un horrible cochon vicieux crachant à la lettre sur le genre humain, ayant à la mode des sarrazins plusieurs femmes, bien qu'aucune ne soit légitime, si ce n'est la première, la reine Blanche des Gaules, un lion tout prêt à verser le sang humain, un ours d'un cœur très dur envers les siens, une vipère rompant le côté de sa propre nation, un serpent qui vole et qui absorbe les dragons volants ${ }^{102}$, les évêques, religieux et les clercs, un dépeuplateur du royaume et du petit peuple, un pourfendeur des fils de son père, un persécuteur en forme de loup, se mariant avec une seconde épouse avec un sacrement ecclésiastique, un contempteur de l'Église et des prélats, quelqu'un de publiquement méprisable ${ }^{103}$. Ce texte ne traduit pas seulement l'aversion que Roquetaillade

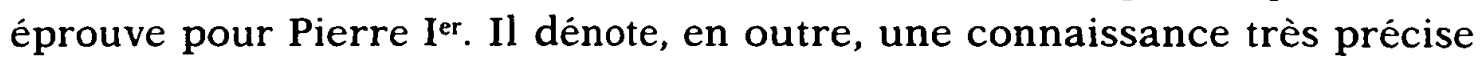
de certains événements secondaires, comme le mariage du roi avec Juana de Castro avec la bénédiction de l'évêque de Salamanque. Remarquons au passage la vieille répulsion de notre auteur pour l'islam, synonyme de dérèglement sexuel.

La présence de Pierre ${ }^{\text {er }}$ devient obsessionnelle dans la psyché de Jean de Roquetaillade. Sa fixation sur ce personnage est telle qu'elle aboutit à deux cauchemars dont le Liber Ostensor nous transmet un récit détaillé. Le premier de ces rêves a lieu en 1356, "douzième année de mes prisons et martyres» ${ }^{104}$, et a Toulouse pour cadre. C'est devant la porte de l'église des mineurs de cette ville qu'il assiste à l'arrivée solennelle de Pierre $I^{e r}$. Le cortège du monarque est composé par des chevaliers qui portent les têtes des saintes Catherine et Agathe. Après cette première rencontre, Roquetaillade est transporté sur la rue qui mène aux armuriers, entre la faculté des arts et le mur du couvent des prêcheurs. Il contemple encore la même procession royale, mais cette fois-ci Pierre Ier le repère, se retourne contre lui et peu s'en faut pour que ses chevaux l'écrasent. Il réussit in extremis à se cacher derrière des étals où l'on vend

102 De radice enim colubri egredietur regulus et semen ejus absorbens volucrem, Is $14,29$.

${ }^{103}$ Cum igitur prefatus rex Petrus Castelle, sicut est publica vox et fama, sit yrcus luxuria fetidus, porcus horribilis spinnosus, ad literam spuens supra modum humanum, more sarracenico plures uxores habens, licet nulla sit legitima, nisi prima regina Blanca gallica, leo ad humanum sanguinem effundendum promptissimus, ursus duri cordis ad suos, aspis rumpens latera proprie nationis, regulus volans absorbens volucres episcopos, religiosos et clericos, depopulator regni, vulgi promiscui, devastator filiorum patris sui, persequtor lupinus, contrahendo cum secunda uxore ecclesiastici sacramenti, contemptor ecclesie et prelatorum, publicus parvipensor, L.O. fo $60 \mathrm{v}^{\circ}$.

104 Annus XII carcerum et martiriorum meorum, L.O. fo 61. 
du parchemin. Soudain un sanglier fait irruption, qui blesse avec ses défenses son tibia fracturé. Atterré, Jean de Roquetaillade prie Dieu et le songe s'évanouit aussitôt. Ce qui est frappant dans ce rêve est la précision avec laquelle la topographie urbaine est retracée: ce sont les lieux hantés pendant une jeunesse perdue que le visionnaire évoque dans son univers onirique avec nostalgie. La répugnance qu'il manifeste à l'égard de Pierre $\mathrm{I}^{\mathrm{e}}$, qui prend une forme porcine pour accroître ses souffrances attaquant sa blessure, ne sort que plus renforcée de ce cauchemar. L'attitude de Roquetaillade frôle la paranoïa de celui qui, dans son délire, se sent persécuté par un être qu'il n'a jamais rencontré.

Le second des rêves relatifs à Pierre $\mathbf{I}^{\text {er }}$ se déroule au cours de la rédaction du Liber Ostensor et, plus précisément, le 27 juin 1356. Pendant son sommeil, il est transporté dans une énorme église des Espagnes où le jeune Pierre doit être couronné. Jean de Roquetaillade prend aussitôt la parole et enjoint à l'adolescent de prononcer sur le champ le vœu de détruire les sarrazins. Les grands du royaume, qui assistent à l'office à droite de la nef, contestent aussitôt le point de vue de notre prophète qui n'en finit décidément pas de jouer le rôle de l'incompris. Il rencontre ensuite le futur roi, vêtu de blanc, faible enfant de quinze ans, tellement infirme qu'il a du mal à tenir sur ses jambes. Il le mène près de l'autel. Là, il le prie de jurer, devant le corps du Christ qui descendra lors de la messe de son couronnement, d'anéantir les musulmans. Mais à sa grande déception, personne ne se présente comme prévu pour célébrer l'office ni pour couronner l'adolescent. À la lumière de ce songe, Roquetaillade conclut que nulle mission messianique n'est réservée à Pierre Ier parce qu'il n'a point reçu d'onction ni ceint de couronne: il n'est ni la chauvesouris, ni le fils du roi des Attalons, ni le lion hispanique qui rugit jusqu'à Sion dont parlent les oracles; jamais il n'établira la monarchie australe ${ }^{105}$. Il est tout au plus Néron, dépourvu de vocation eschatologique, indigne même de recevoir le titre d'Antéchrist occidental, à qui revient l'office honorifique de combattre son homologue islamique, alors qu'on sait le prestige que tirait la couronne d'Aragon de l'appropriation de ses attributs.

Ces deux rêves n'ont rien de prémonitoire : leur place dans le système prophétique du Liber Ostensor n'est pas de prédire le futur, mais de désigner le pervers. Ils se situent dans le plus proche des présents, si grande est leur portée politique. L'impossibilité de Pierre $\mathbf{I}^{\text {er }}$ à prononcer son vœu de lutter contre les musulmans, correspond à des événements

105 L.O. fo $62 v^{\circ}-63 r^{\circ}$. 
qui ont occupé la papauté avignonnaise depuis quelques mois. En 1354, un projet de croisade contre le royaume de Grenade semble avoir été envisagé par Pierre ${ }^{\text {er }}$ qui en fit part à Innocent VI (1352-1362) dans sa correspondance; il prétendait alors compter sur l'appui du parti d'un tel Abdallah disposé à combattre les Nasrides; le pape l'avait encouragé dans ses missives à s'engager dans cette voie ${ }^{106}$. Mais le tout fut vite abandonné par Pierre I $^{\text {er }}$ qui comprit l'intérêt qu'il avait à obtenir la neutralité voire l'alliance de Muhammad V (1354-1391) face à ses multiples ennemis. On n'aura pas de mal à imaginer la déception d'Innocent VI ni à insister sur l'influence de la politique papale sur l'œuvre de Jean de Roquetaillade qui blâme les hésitations de Pierre Irer, dont les mœurs sont musulmanes, à faire la croisade.

D'autres contentieux, combien plus importants, existaient entre Innocent VI et Pierre $\mathrm{I}^{\mathrm{er}}$. Le jeune roi de Castille concevait la fonction royale comme beaucoup de monarques du XIVe siècle : le renforcement des institutions royales, le développement de l'État et le centralisme étaient prédominants dans son programme politique ${ }^{107}$. Dans son élan pour accrồtre les prérogatives de sa couronne aux dépens des pouvoirs traditionnels, il devait heurter un jour l'Église. Son règne est émaillé de conflits avec Innocent VI. Le problème de la perception des dîmes, qu'il retient systématiquement au détriment du Saint-Siège, est une de ces multiples pierres d'achoppement. Le droit de régale est également une source de litiges, tandis que Pierre $I^{\text {er }}$ entretient à bon escient la vacance des sièges épiscopaux aussi bien pour en percevoir les revenus que pour affaiblir l'emprise des évêques dans la vie politique du royaume. À partir de mai 1356, il s'oppose, d'ailleurs, au versement des rentes des clercs bénéficiaires, qui ne résideraient pas en Castille, sans doute comme mesure d'extorsion contre les nombreux exilés qui contestent sa domination. Il n'est donc guère étonnant de trouver bon nombre de prélats - comme les évêques de Ségovie et de Sigüenza - du côté de Ferdinand d'Aragon et d'Henri de Trastamare quand éclate la révolte en 1354. Les légats pontificaux sillonnent, en outre, les routes de la Castille sur laquelle ils jettent l'interdit en janvier 1355. La situation entre le Saint-Siège et Pierre $I^{\text {er }}$ est donc des plus tendues à l'époque où Jean de Roquetaillade rédige son Liber Ostensor: il n'en faut pas plus pour que le roi de Castille devienne la bête noire

106 Lettres éditées dans les annexes de G. Daumet, Innocent VI et Blanche de Castille, Paris, 1899.

107 J. VALDEón, León y Castilla, dans M. Tuñón de Lara (dir.), Historia de España, Barcelone, 1980, p. 143-167. 
de notre prophète, tout comme la française Blanche, qui subit les outrages de ce deuxième Néron, est l'objet de sa prédilection.

\section{Blanche de Bourbon, "colombe blanche»}

Dans sa correspondance, Innocent VI a maintes fois reproché à Pierre $I^{\text {er }}$ la répudiation de son épouse, l'accusant de commettre le même péché que Samson, David et Salomon et d'exposer ainsi son royaume aux pires malheurs ${ }^{108}$. Le style épistolaire du Souverain Pontife est, comme l'on pourrait s'en douter, bien plus sobre que les folios que Jean de Roquetaillade consacre à Blanche dans le Liber Ostensor: c'est avec passion qu'il décrit la triste destinée de cette «blanche colombe», rejetée par son mari «écumant et féroce comme un sanglier»109. Voici les idées qu'évoquent en lui la prophétie de Merlin «l'Espagnol, dont il était dit jusqu'à présent qu'il dormait »: «Il est plus clair que le soleil que, depuis la mort de son père, il semble dormir avec sa concubine dans des très graves péchés, dans la nuit des tribulations des guerres, après avoir rejeté Blanche, la reine légitime. Et il dort bien! Car, au pied de la lettre, pour une horrible et vieille veuve, blessée, difforme et noire, il a rejeté la reine, son épouse légitime, Blanche, issue de la très noble race des Francs, une fleur, comme l'on dit habituellement de toutes les femmes du monde qui ont la beauté du corps et de l'esprit et la fidélité conjugale »110. Les malheurs de cette jeune princesse - dont le seul prénom évoquait déjà la pureté par opposition au hâle luxurieux de la maîtresse du roi -, avaient de quoi attendrir Jean de Roquetaillade. Elle était de surcroît française et l'attachement de notre auteur aux Valois ne pouvait que le pousser à davantage de compassion.

À nouveau, le rôle que Jean de Roquetaillade accorde à l'un des acteurs de sa tragédie espagnole est déterminé par des coulisses où la politique devient la vraie diva. 1356 est l'année de Poitiers et Jean le Bon,

108 DaUmet, Innocent VI. ., annexes.

109 Petrus, prefatus rex Castelle, qui ad literam est spumosus et ferox ut porcus singularis, expulit columbam albam scilicet, Dominam Blancam, uxorem legitimam suam, L.O. fo $61 v^{\circ}$.

110 Clarum est clarius sole quod a tempore mortis patris sui in peccatis gravissimis dormire videre in nocte tribulationum bellorum cum concubina sua, Blanca legitima regina comptempta. Et bene dormire quia ad literam pro una terribili vetula vidua perforata deformis et nigra, contempsit reginam uxorem suam legitimam Blancam nobilissimis Francorum ortam natalibus, florem ut communiter dicitur omnium mulierum mundi in pulcritudine corporis et honestate maritali et mentis, L.O. $f^{\circ} 59 v^{\circ}$. 
dans sa captivité, devait affronter des affaires bien plus pressantes que le succès de ce mariage espagnol : depuis des années, d'ailleurs, la situation de son pays le rendait insolvable de la dot de trois cent mille florins, ce qui a été interprété par certains historiens comme la vraie raison du divorce de Pierre $I^{\text {er } 111}$. Le roi de France se déchargea donc de cette affaire sur la personne d'Innocent VI : jamais un ambassadeur de Jean II ne fut dépêché en Castille à ce sujet! En revanche, Innocent VI écrivit autant de lettres de consolation à Blanche qu'il reçut les émissaires de la princesse - le vicomte de Narbonne et Ottobono da Oliva, son trésorier génois - ou qu'il envoya des légats auprès d'elle. Jean de Roquetaillade les a peut-être fréquentés: il mentionne, en tout cas, Bertrand, évêque de Sénez (1326-1358), qui reçut une bulle commissionnaire datée du 7 mai 1354 pour juger les évêques d'Avila et Salamanque et excommunier Pierre $I^{e r 112}$, ainsi que Guillaume de la Jugie, cardinal de Sainte-Marie in Cosmedin, parti en Castille à la fin de l'année 1355 pour lever l'interdit ${ }^{113}$. La navette de tous ces personnages entre la péninsule Ibérique et le palais des Papes apportait de nouvelles fraîches à Jean de Roquetaillade qui avait de quoi tenir ses chroniques au jour le jour ${ }^{114}$.

\section{Ferdinand d'Aragon, "chauve-souris»}

Aux yeux de Jean de Roquetaillade, Pierre Ier est indigne d'exercer la fonction royale. La révolte de ceux qui le combattent est juste: parmi ses meneurs, il se trouve l'infant Ferdinand d'Aragon sur lequel notre prophète fonde tous ses espoirs; un jour il devrait remplacer le méprisable Néron sur le trône de Castille. L'infant était né du second mariage d'Al-

111 J. B. Sitges, Las mujeres del rey don Pedro Io de Castilla, Madrid, 1910, p. 361 .

112 D'après le témoignage de Jean de Roquetaillade, il ne parvint jamais à franchir la frontière du royaume de Castille: Episcopum etiam Dignensem, legatum apostolice sedis, directum $a b$ ipsum ut ab intento secunde uxoris quam sollempniter regina Blanca vivente in ecclesia more matrimoniali publice acceperat per mandatum apostolice sedis recederet intra suum regnum sub pena mortis vetavit intrare in contemptum maximum Ecclesie generalis romane, L.O. fo. $62 \mathrm{r}^{\circ}$-vo.

113 Sed jam fama publice inolevit quod hoc anno Domini M.CCC.LXVIto, ad presenciam legati apostolice sedis cardinalis Guillermi, coronari disponit, L.O. fo 59ro.

114 Il nous apprend ainsi le froid qui s'est abattu sur la région, déjà fort affamée, de Tolède, à la mi-mai 1356 et qui risque de donner de mauvaises rècoltes pour l'été : in regionibus toletanis, ubi comederunt homines omnes canos et murilegos et asinos, post animalia comedi consueta, et nunc in medio madii, bladis, gelu combustis, majus malum paratur et ipse in XXII anno consistens amplius invalescit ad destruendum regnum, L.O. fo $62 \mathrm{r}^{\circ}$. 
phonse IV (1327-1336), roi d'Aragon, qui avait épousé - peu après la mort de sa première femme Teresa d'Entença en 1327 -, Léonor, sœur d'Alphonse XI de Castille. Il était donc le demi-frère de Pierre IV d'Aragon et le cousin germain de Pierre Ier de Castille. Cette position prestigieuse au sein des deux familles royales le prédisposait à un avenir prometteur, en raison de ses droits à la succession de deux monarques dont la descendance - masculine pour l'un, légitime pour l'autre - tardait à venir. Elle le rendait, de plus, membre à part entière du groupe puissant et turbulent des cadets de la famille royale qui détiennent un grand pouvoir aussi bien politique qu'économique dans les royaumes ibériques du bas moyen âge ${ }^{115}$. En 1336, peu après avoir ceint la couronne d'Aragon, Pierre IV avait expulsé de son royaume sa marâtre Leonor et ses deux demi-frères, Ferdinand et Juan, pour éviter d'éventuelles contestations. Nous l'avons $\mathrm{vu}$, l'infant Ferdinand était revenu en force dix ans plus tard, prenant la tête de la révolte des unions de Valence et d'Aragon, grâce auxquelles il faillit détrôner le Catalan. Refoulé de nouveau en Castille, il jouait encore un rôle de premier plan sur la scène politique. Le testament d'Alphonse XI le nommait son successeur dans le cas où Pierre I ${ }^{\text {er }}$ viendrait à mourir sans enfant; en 1350, lors de la maladie du jeune monarque, il était déjà pressenti comme roi de Castille. Très vite, il passait au camp des opposants de son cousin, participant activement aux événements de Tolède et Toro en 1354; il venait alors d'épouser Marie, infante de Portugal, dont la maison était également hostile à Pierre $\mathbf{I}^{\mathrm{er}}$. Mais après les défaites de 1355, il retournait en Aragon avec Henri de Trastamare et ses partisans. Pierre IV les accueillait volontiers et préparait une contre-attaque contre la Castille, profitant du renversement des alliances et recherchant l'appui de la maison de France. Dans un premier temps, Ferdinand était nommé procureur général d'Aragon et reprenait son titre de marquis de Tortosa, mais il tombait vite en disgrâce; en 1360, ses partisans pénétraient en Castille et essuyaient la défaite de Nájera; en 1363, à la suite de la trêve de Murviedro entre les rois d'Aragon et Castille, sa suppression - dans laquelle Henri a dû peser lourd - était décrétée; les hommes de main de Pierre IV l'assassinaient à Castellón. La voie qui menait le comte de Trastamare vers la couronne de Castille était largement dégagée.

Toutefois, l'été 1356, aux yeux du plus grand nombre, Ferdinand apparaît comme le seul remplaçant en droit du tyran. Henri est certes

115 Cf. I. Beceiro PItA, Los dominios de la familia real castellana (1250-1350), dans A. Rucquor (dir.), Genèse médiévale de l'État moderne : la Castille et La Navarre (1250-1370), Salamanque, 1987, p. 79-106. 
fort de ses vastes domaines andalous et de ses clientèles, mais sa bâtardise semble un trop lourd empêchement. C'est pourquoi Jean de Roquetaillade fonde tous ses espoirs sur l'infant d'Aragon, qui n'est autre que la chauve-souris de l'oracle d'Arnaud de Villeneuve: "Prend l'éventail, tue les mouches' veut dire expressément que, après que ce pape futur ait tué ce Néron avec le glaive spirituel de la bouche du Christ, il fera mettre à sa place, à la tête du royaume de Castille, quelqu'un d'autre de race royale, un des fils du roi d'Aragon et de Léonor, sœur d'Alphonse, père du dit Pierre, cochon néronien. Ceux-ci sont deux : Ferdinand et Juan, parmi lesquels Ferdinand porte sur son casque la chauve-souris, symbole de ses armes. Il est donc clair que celui-ci, de père aragonais et de mère castillane, est la chauve-souris, destructeur de sarrazins, qui serait l'éventail entre les mains du futur pape qui le prendrait pour anéantir les mouches importunes sarrazines; il est aussi le lion espagnol dont on parle plus haut dans l'oracle de Merlin "116. Certes, c'est de façon abusive que Jean de Roquetaillade parle du cimier en forme de chauve-souris de l'infant Ferdinand: l'animal emblématique du casque des rois d'Aragon à partir de 1344 était, en fait, le dragon volant de l'Apocalypse ${ }^{117}$. Mais il est aussi vrai que cette confusion était fort répandue et que Roquetaillade n'en était pas à une erreur près pour faire coïncider les prophéties anciennes avec l'actualité politique.

Le dévolu que le franciscain de la prison du soudan jette sur Ferdinand ne s'explique pas sans l'existence en Avignon d'un parti fondant ses espoirs sur un concurrent de Pierre $I^{\text {er }}$ à la couronne de Castille. Jean de Roquetaillade se fait l'écho des options de ce groupe de pression au sein de la curie qui le met au courant de la situation politique de la péninsule. Parmi ses têtes de file, il n'est pas difficile de placer Gil de Albornoz, qui s'était réfugié dans le palais des Papes après qu'en 1350 le jeune Pierre Ier eût

116 Accipe flabellum, interfice muscas expresse vellet dicere quod postquam prefatus papa futurus interfecisset gladio spirituali oris Christi Neronem istum, faceret prefici in regno Castelle alium loco sui de genere regali, unum ex filiis regis Aragonie et Helionoris sororis Alphonsi patris prefati Petri Nerioniani porci. Sunt enim duo Fernandus et Johannes, quorum Fernandus super galeam vespertilionem gerit insigne armorum et tunc clarum esset quod ille ex patre aragonensi et ex matre castellana esset vespertilio destructor sarracenorum, qui foret flabellum in manu futuri pape assumendum ad muscas importunas sarracenicas perimendum, et esset leo ispanus de quo superius in vaticinio eloquitur Merlinus, L.O. fo $61 \mathrm{r}^{\circ}$.

11 A. Milhou, La chauve-souris, le nouveau David et le roi caché, dans Mélanges de la Casa de Velázquez, 1981, p.61-78. Cf. en outre M. PASTOUREAU, Du masque au totem: le cimier héraldique et la mythologie de la parenté à la fin du Moyen Âge, dans Razo, 6, p. 39-63. 
écrasé Leonor de Guzmán et sa camarilla. Par la suite, l'ancien archevêque de Tolède devait intervenir avec succès dans la reconstitution des états pontificaux en Italie centrale l'année 1354; dans un passage du Liber Ostensor, Roquetaillade dit toute son admiration pour les victoires du prélat castillan, parlant avec enthousiasme des «guerres du cardinal d'Espagne, légat du siège apostolique, contre les tyrans qui occupent le patrimoine de saint Pierre, à savoir : le tyran qui se faisait appeler préfet de Viterbe, le tyran dit Malatesta qui occupe la Marche d'Ancône et le tyran qui dans le comté de Romagne se fait appeler capitaine de Forli»18. Tandis qu'il vante les mérites de Gil de Albornoz qui lutte au service de la papauté, il devient le porte-parole de ses sympathies pour les ennemis de Pierre Ier.

Un autre prélat castillan, parent de Gil de Albornoz, a dû inspirer Jean de Roquetaillade dans son adhésion au parti de Ferdinand d'Aragon : il s'agit de Pero Gómez Barroso, évêque de Sigüenza, qui avait pris part active au soulèvement de Tolède et qui, après la prise de la ville par Pierre Irer, avait pu fuir la Castille, grâce à la pression du légat Guillaume de la Jugie, et arriver en Avignon en compagnie du trésorier de Blanche en juin 1355. Notre auteur tient sans doute de sa bouche le récit qu'il rapporte à son sujet : "(Pierre $I^{\text {er}}$ ) enferma l'évêque de Sigüenza, neveu du cardinal d'Espagne, et lui vola d'innombrables trésors qui appartenaient à ce cardinal et le sortit avec des habits pontificaux (épiscopaux), monté de façon ignominieuse sur un âne, le visage tourné vers la croupe. Il le précédait en ville en proférant d'une voix de crieur des mots blasphématoires contre le Dieu du ciel et contre l'Église. Ensuite, il l'envoya en exil avec les membres de sa famille qu'il n'avait pas tués. Voici donc ce que cet évêque est devenu pour appuyer la reine Blanche, épouse légitime du roi, contre la prostituée que celui-ci a prise en secondes noces "119. Les outrages subis par l'évêque de Sigüenza ne relèvent pas nécessairement de la bouillante imagination de

${ }^{118}$ Et in bellis cardinalis Ispani, legati Sedis Apostolice contra tirannos occupantes patrimonium sancti Petri, scilicet tirannum qui se clamabat prefectum Viterbii, contra tirannum occupantem Marchiam anchomitanam qui dicitur Malatesta, et contra tirannum qui in comitatu Romandiole se clamat capitaneum Forlivii, L.O. fo $65 \mathrm{r}^{\circ}$.

11 Cepit episcopum Segoncie nepotem cujusdam cardinalis Ispani et ipsum spoliavit thesauris innumeris qui fuerant predicti cardinalis et exivit eum habitu pontificali et ignominiose in asino elevantum facie versa contra dorsum asini voce preconia precedente, acclamante verba blasphemie per civitatem predictam in Dei celi et Ecclesie blasfemiam duci fecit et ipsum cum illis de cognatione sua multis tamen occisis in exilium destinavit et demum episcopus sic conversus quia regine Blanche, uxori regis legitime contra meretricem, cum qua contraxit secundo dederat favorem, L.O. fo $61 \mathrm{r}^{\circ}$. 
Roquetaillade: l'humiliation de ce prélat rappelle sur bien des points les autodafés ou les ânes mitrés de l'époque moderne, qui ont bien dû exister aux moments les plus tendus du mouvement communal et de la contestation de la seigneurie épiscopale dans les villes médiévales. En l'occurrence, nous avons affaire à un monarque, porte-parole du centralisme, qui marque de façon symbolique ses différends envers l'Église qu'il perçoit comme un contre-pouvoir à sa domination autoritaire: Pierre IV d'Aragon affectionnait ce genre de manifestations; il fit notammment pendre par les pieds à la fenêtre de son palais un official du pape jusqu'à ce qu'il eût retiré l'excommunication pontificale. L'absolutisme avant la lettre des rois ibériques du XIVe siècle est incompatible avec le rôle politique de la papauté avignonnaise et des prélats de la péninsule.

La méthode d'exposition de Jean de Roquetaillade s'inscrit dans la tradition médiévale de la lectio, de la glose des textes émanant des autorités. Mais son originalité réside dans son attachement suranné au «commentaire boiteux ${ }^{120}$, qui lui fait passer du coq à l'âne ou se contredire d'un folio sur un autre au bon gré du texte commenté : ce manque de logique est, pour le moins, surprenant chez un individu qui a fréquenté l'école des arts de Toulouse où, au XIVe siècle, la rigueur de la scolastique a dû largement s'imposer. Au demeurant, ce sont ses sources qui l'incitent à s'engager dans les voies sinueuses de l'irrationalité : nul ne saurait remettre en question les origines divines des paroles données à Merlin, Cyrille ou Arnaud auxquelles il accorde une crédibilité aveugle. Or, la finalité de l'œuvre de Jean de Roquetaillade est de confirmer la caractère prémonitoire de ces oracles à la lumière d'une histoire dont il entend lire les signes. Le franciscain auvergnat n'est pas tant prophète qu'interprète des prodromes de la fin des temps au double miroir des oracles révélés dans le passé et des événements qu'il voit dans le présent. Il s'ensuit un discours symbolique, aux antipodes de la logique du syllogisme : sa pensée s'accroche à des associations d'idées plutôt qu'à des raisonnements; c'est parce qu'il est le poulain de la jument que Pierre ${ }^{\text {er }}$ sera détrôné un jour par l'infant Ferdinand dont le cimier représente la chauve-souris. À l'heure de désigner bons et méchants sur la scène de l'actualité, des oracles autant que la moralité des acteurs sociaux servent de référence, mais jamais le bien fondé d'une décision princière sur le plan politique ne sera prise en considération.

La réflexion et l'écriture de Jean de Roquetaillade sont pétries d'oralité. Le temps record - à peine quatre mois! - qu'il a consacré à la rédac-

120 Cette expression, utilisée par C. Beaune au cours de son exposé au séminaire de l'U.A. 1011, nous semble convenir parfaitement à l'œuvre de Roquetaillade. 
tion des douze longs traités du Liber Ostensor témoigne de la fébrilité d'une démarche qui est beaucoup plus parlée qu'écrite. Sans «raison graphique»121, sa pensée prend la tournure symbolique que l'on sait. En outre, cette oralité ne transparaît pas seulement dans sa méthode, mais aussi dans la fonction de son œuvre. La matière prophétique qu'il commente et enrichit doit servir à transmettre des messages politiques au sein d'une population à majorité illettrée. Un passage du Liber Ostensor, où Jean de Roquetaillade cite une prophétie entendue de vieille date, vient étayer cette hypothèse : "Néanmoins, frère Géraud de Pescher, que l'on tenait communément dans ma jeunesse pour l'homme le plus subtil ${ }^{122} \mathrm{du}$ monde, que j'ai vu quand il était lecteur à Toulouse, originaire du PuySaint-Front de Périgueux, composa quelques vers qui commencent 'Quam ba caer, veyrem' dans lequel il est dit qu'Édouard (III), à ce jour roi d'Angleterre, à présent, après avoir vaincu le roi de France, doit accéder à l'Empire romain, détruire la superbe du clergé, réparer l'Église, soumettre les sarrazins et il dit d'autres choses étonnantes à son sujet ${ }^{123}$. Ce qui semble intéressant dans ce texte est la mention de la chanson politique de Géraud de Pescher, véritable sirventes à la façon de Bertran de Born, le troubadour périgourdin du XII ${ }^{e}$ siècle; cet oracle en vers jouit probablement d'une large diffusion orale: Jean de Roquetaillade était capable de s'en souvenir trente ans après l'avoir entendu et nous en conservons au moins une copie sous forme d'annotation marginale faite à la fin du XIVe siècle sur une Bible du siècle précédent ${ }^{124}$. Au cours de ce colloque, N. Lemaître et $\mathrm{C}$. Beaune ont présenté un Karolus, pamphlet rouergat copié en

121 Cf. J. Goody, La raison graphique, Paris, 1979.

122 Ayant participé à la querelle de la vision béatifique sous Jean XXII, il est probable que cet adjectif s'applique à la prise de position de Géraud en faveur de la subtilité des corps, cf. Histoire littéraire de la France, t. XXXVI, Paris, 1927, p. 601-604.

${ }^{123}$ Frater autem Geraldus de Piscario, qui tempore juventutis mee subtilior homo mundi dicebatur communiter, quem vidi lectorem Tolose, qui erat de Petragoris, de monte Sancti Frontonis, composuit quosdam versus qui incipiunt "Quam ba caer, veyrem", in quibus dicit hodiernum Hodoardum, regem Anglorum per cum presens, superato rege Francorum, debere ascendere ad romanum imperium et destruere cleri superbiam et ecclesiam reparare, subicere insuper sarracenos et alia stupenda dicit de ipso, L.O. fo $16 \mathrm{v}^{\circ}$.

124 Cette Bible avait été découverte en $1927 \mathrm{chez}$ un libraire de Genève par Jeanne Bignami-Odier. Le vrai incipit de ce poème en quarante décasyllabes est Em breu, veyrem una freior abatre. Nous n'avons su trouver l'édition d'E. Muret annoncée dans Histoire littéraire de la France, t. XXXVI, Paris, 1928, p. 656. Cette référence nous a été aimablement communiquée par $\mathrm{S}$. Barnay. 
1467, favorable au dauphin Charles, comte d'Armagnac: cet oracle politique, rédigé en latin, circulait sans doute sous forme de feuille volante et pouvait faire l'objet d'une traduction de vive voix en langue d'oc à l'attention d'un public sensible aux arcanes de ses messages acrostiches. Ce sont là autant d'exemples qui témoignent de la diffusion orale de cette littérature prophétique fortement politisée: de bouche à oreille, le rayon d'action et la longévité de ces oracles étaient grands, comme le prouve le succès ultérieur en Méditerranée Occidentale des thèmes développés dans le Liber Ostensor au sujet du roi de Castille.

\section{UN FUTUR IDÉOLOGIQUE}

L'histoire de Pierre Ier finit mal. En 1360, à la suite de la paix de Brétigny entre les rois de France et d'Angleterre, Pierre IV peut faire appel à Bertrand Duguesclin et aux compagnies blanches dans son combat contre le roi de Castille qui obtient, de son côté, l'appui du Prince Noir et ses troupes. La guerre des cent ans a désormais la péninsule Ibérique pour théâtre. Les opérations militaires entre Henri de Trastamare, appuyé par les Catalans et les Français, et Pierre Ier et les Anglais ne seront guère arrêtées que par quelques trêves obtenues par le cardinal de Bologne. Le roi de Castille remporte les deux victoires de Nájera (1360 et 1367), mais Henri aura le dernier mot, en le battant à la bataille de Montiel (1369). Devenu à cette date roi de Castille, le comte de Trastamare ne se contente pas seulement d'assassiner de ses propres mains son rival de toujours, mais s'en prend également à son image. Pour justifier une intronisation plus que contestable, il exploite le messianisme de sa mission et la légende noire de Pierre Ier, thèmes qui apparaissent d'une précocité remarquable sous la plume de Jean de Roquetaillade.

Les documents de la chancellerie d'Henri de Trastamare reflètent le besoin que le prétendant au trône avait de hausser sa guerre au rang d'une véritable croisade. Le préambule d'un document daté du $1^{\text {er }}$ avril 1366 parle ainsi de «la destruction de nos terres par le méchant tyran, ennemi de Dieu et de notre sainte mère l'Église, (. . .) augmentant et enrichissant les maures et les juifs (. . ), abaissant la foi catholique» ${ }^{125}$. Après sa victoire, le thème de la cruauté et la tyrannie de Pierre ${ }^{\text {er }}$ revient souvent dans les discours du nouveau roi dans les assemblées représentatives; les membres des cortes, dont le rôle avait été mis en question par le 
centralisme du monarque assassiné, approuvent son point de vue. Les chroniques officielles rappellent à satiété les crimes du monarque défunt : l'humaniste Pero López de Ayala (1332?-1407) - qui après avoir été un fidèle serviteur de Pierre I Ier devenait conseiller d'Henri I ${ }^{\text {er }}$-, fait de la mort de Leonor de Guzmán et de Léonor d'Aragon des crimes perpétrés par son ancien maître; il nous apprend qu'après la prise de Tolède Blanche de Bourbon avait été transféré de prison en prison pour être finalement empoisonné, sous l'ordre de son mari, à Medina Sidonia en $1361^{126}$. Le romancero, chanson propulaire castillane, s'appropriait l'histoire des infortunes de la princesse étrangère délaisée par son mari, sujet de rêve pour ses complaintes ${ }^{127}$ : les déboires de la jeune fille avaient de quoi attendrir plus d'un cœur sensible disposé à se rallier au remplaçant du cruel époux de Blanche. Sciemment exploités par la propagande Trastamare, les drames domestiques de la cour de Castille servaient à redorer le blason d'Henri Ier qui en avait bien besoin.

Mais c'est surtout dans la Catalogne d'un Pierre IV, allié du comte de Trastamare, que l'œuvre de Jean de Roquetaillade est la plus utilisée pour blâmer Pierre Ir. En 1377, l'infant Pierre d'Aragon, que nous avons ren-

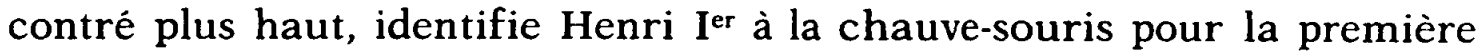
fois; il commente, à cette date, le message qu'un moine cistercien avait reçu à Tripoli au sujet du cèdre du Liban et met en place une constellation où le nouveau roi de Castille voltige parmi les étoiles des derniers coups de théâtre militaires: Pierre Ir, poulain de la jument, devient Saturne - la plus haute et méchante des planètes -, Pierre IV, Mars et le Prince Noir, Jupiter ${ }^{128}$. Le cadavre de l'infant Ferdinand d'Aragon - dont Roquetaillade vantait jadis les qualités cheiroptériques - est mis dans le placard des amnésiques de l'histoire. Un transfert de la mission messianique des Catalans, descendants de Frédéric II, s'amorce alors au profit des Trastamares, qui usurperont une nouvelle royauté, en l'occurrence aragonaise, en $1412^{129}$. Ce n'est pas par hasard si les descendants d'Henri I $^{\text {er }}$ accaparent au $\mathrm{XV}^{\mathrm{e}}$ siècle les symboles de la chauve-souris, du nouveau David et du lion rugissant, tandis que la Castille, forte d'une reprise démographique précoce après les crises des années 1348, devient la puissance prépondérante de la péninsule Ibérique.

126 Crònica de los reyes de Castilla, t. I, Madrid, 1779, p. 272 et 328.

127 De Borbón, dice soy hija, / de Carlos delfin cuñada, / y el rey de la flor de lis pone en su escudo mis armas (...) caséme en dia aciago, / martes fue por la mañana, I y el miércoles enviudaron / el tálamo y la esperanza, cit. DAUMET, Blanche...

128 R. E. LeRner, The Powers of Prophecy, Berkeley, 1983, p. 144 et 220-221.

129 Milou, Colón. .., p. 380 et 387. 
Dans le royaume de France, outré par l'alliance entre le roi de Castille et l'Angleterre, les infortunes de la fille du duc de Bourbon eurent un retentissement certain. À la cour du moins, l'infidélité de Pierre Ier fut maintes fois décriée. Cela ressort particulièrement d'une annotation écrite au dos du parchemin qui contient le contrat de mariage entre le roi de Castille et Blanche de Bourbon le 7 juillet 1352: quelques années plus tard, un membre de la chancellerie royale y donnait sa vision des événements: «Ce mariage fut consommé, mais le roi Pierre fit mourir son épouse de façon traîtresse, fort inhumaine et infidèle. C'est pourquoi, par ce qui semble être un juste jugement de Dieu, il fut dépouillé de son royaume et expulsé; finalement, comme il se doit, il fut virilement tué par le roi Henri, son adversaire ${ }^{130}$. Les Trastamares s'assuraient ainsi l'appui de la couronne de France.

Mais c'est surtout en Avignon que le tableau des méfaits de Pierre Ier devait être le plus noirci. La première vie d'Innocent VI, écrite en France à la fin du XIVe siècle contient la plus ancienne version de la légende du sortilège de Samuel Lévi ${ }^{131}$ : au lendemain des noces entre Pierre et Blanche, ce juif, trésorier du roi, et María Diaz de Padilla, sa concubine délaissée, auraient ourdi un plan pour faire échouer le mariage; ils offrirent une ceinture en or, soumise aux incantations de Samuel, à Blanche pour qu'elle la remît au roi; la princesse la donna solennellement à son mari devant toute la cour, mais aussitôt la ceinture devient serpent en même temps qu'une horrible aversion pour sa jeune épouse naissait dans le

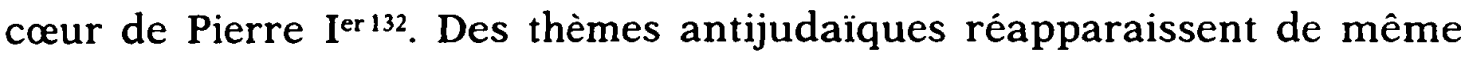
dans la quatrième vie d'Urbain $\mathrm{V}$ : le pape s'engagea dans une discussion théologique avec le cardinal d'Ostie au sujet de la mort du roi de Castille; il demanda à son interlocuteur s'il était moral de se réjouir de la disparition de Pierre $I^{\text {er }}$ "car il était rebelle à l'Église, défenseur des sarrazins et des juifs et, comme un infidèle, propagateur des infidèles ${ }^{133}$. Cet antisé-

130 Fuit consumatum matrimonium, sed dictus rex Petrus fecit proditionaliter et inhumanissime ac infidelissime mori dictam uxorem suam. Quamobrem, justo Dei judicio, ut creditur, fuit a regno suo spoliatus et expulsus, et finaliter per regem Henricum, suum adversarium, viriliter et debite interfectus. Paris, Archives nationales, $\mathbf{J}$ 603.

131 G. Mollat, Etude critique sur les Vitae paparum Avenionensium d'Étienne Baluze, Paris, 1917, p. 71 n. 1.

132 É. Baluze, Vitae paparum Avenionensium, Paris, 1693, col. 324-326.

133 Pro eo quia rebellis erat Ecclesiae, fautor sarracenorum et judaeorum et quasi infidelis infidelium propagator, Baluze, Vitae..., t. I, col. 422. Cf. col. 326, 386 et 405. 
mitisme a dû être emprunté à la propagande Trastamare en Castille qui affirmait, entre autres, que Pierre Ier n'était pas le fils d'Alphonse XI, car il avait été changé dans son berceau par Pero Gil, un enfant juif ${ }^{134}$. La politique de Pierre $I^{\text {er }}$ avait, en effet, été très favorable aux juifs: en échange de leur appui économique, il leur avait accordé sa protection et des postes très en vue dans l'administration. Or, à la paire des victoires d'Henri $I^{\text {er }}$, faisaient suite en Castille les pogroms et la haine qui devaient aboutir à l'expulsion des juifs de $1492^{135}$.

À partir d'Avignon, les thèmes hostiles à Pierre Ier $^{\text {arrivent dans les }}$ républiques du nord de l'Italie. Le florentin Matteo Villani, qui poursuit la chronique de son frère Giovanni entre 1348 et 1363 , écrit au sujet du «tyran inique»: «Je ne me souviens d'avoir jamais lu qu'il y eût autant d'injustice, d'impiété et de cruauté dans un roi chrétien ${ }^{136}$. Dépassant les frontières des États qui avaient participé à la guerre de Castille, le sujet de la tyrannie de Pierre ${ }^{\text {er }}$ atteint ainsi la Toscane : la chrétienté est unanime sur le bien fondé de l'élimination du roi au nom du tyrannicide. Belle victoire de la noblesse, les «comunidades» et l'Église dans leur combat idéologique contre Pierre Ier!

Jean de Roquetaillade a contribué de façon décisive à diffuser la légende noire contre le roi de Castille. Sous sa plume, les thèmes hostiles à Pierre I ${ }^{\text {er }}$ se mettent en place à une date extrêmement précoce. Des renseignements très précis sur l'évolution de la guerre civile en Castille lui permettent d'exposer avec conviction les raisons de son choix en faveur de l'infant Ferdinand. Il tire ces informations du milieu politique du palais des Papes d'Avignon dans lequel il est très bien introduit et dont il devient redevable pour les nouvelles qui lui permettent de peindre sa vaste fresque apocalyptique. De la sorte, il est acquis au discours du personnel de la curie qui est celui des heureuses retrouvailles de la monarchie française et de la papauté installée en Avignon : sa fidélité à Innocent VI et à Jean II se manifeste dans ses prises de position à l'encontre des Aragonais de Sicile et de Pierre $I^{\text {er }}$. En 1356, ses options sont celles de ses protecteurs.

Toutefois, son œuvre, imprégnée qu'elle est de modernité, dépasse

134 J. VALDEÓN, Enrique II de Castilla : la guerra civil y la consolidación del régimen (1366-1371), Valladolid, 1966, p. 96-99.

135 J. VAldeÓN, Los judios de Castilla y la revolución Trastámara, Valladolid, 1968, p. 25-30.

${ }_{136}$ Quello iniquo tiranno (...) tanta ingiustizia, tanta empietà e crudeltà fosse in alcuno re cristiano, non mi ricordo d'avere letto giammai, cité par J. GIMENO CASALDUERO, La imagen del monarca en la Castilla del siglo XIV, Madrid, 1972. 
largement les contingences d'un présent politique où elle ne saurait se cantonner. Jean de Roquetaillade écrit au moment où une crise sans précédent entraîne un renversement de la position royale: d'arbitre et de garant d'un droit préexistant, le roi se transforme en source de loi tandis que l'utilité publique se confond avec ses propres intérêts ${ }^{137}$. Sous Pierre IV, s'en est provisoirement fini avec l'accord tacite qui régissait les rapports entre le monarque et les différents acteurs collectifs de la confédération catalano-aragonaise; il en va de même dans la Castille de Pierre I $^{\text {cr }}$ dont l'autoritarisme heurte la noblesse, le clergé et les conseils urbains ${ }^{138}$. De nouveaux courants d'idées accompagnent cette genèse de l'État: ils sont de plus en plus colportés par la prophétie. L'infant Pierre d'Aragon, oncle et mentor du roi, écrit aussi bien un De regimine principum, destiné à justifier la toute-puissance de la couronne, que des commentaires aux oracles des spirituels. Il suit une démarche messianique qu'il a précisément empruntée à notre visionnaire. L'œuvre de Jean de Roquetaillade représente une des premières tentatives conscientes et systématiques de donner à la prophétie une dimension politique. Elle est un jalon décisif dans l'histoire du joachimisme qui aboutit aux utopies idéologiques de l'époque contemporaine.

Martin AurelL

137 G. GIORdanengo, Du droit civil au pouvoir royal (XIIe-XVe siècle), dans Public, privé : espaces et gestions, Lyon, 1987, p. 9-25.

138 Pour une réflexion de fonds sur la nature de ces pouvoirs, cf. F.-X. Guerra, Acteurs sociaux et acteurs politiques, dans Structures et cultures dans les sociétés hispaniques au-delà du modèle socio-économique, Bordeaux III, 1988 (à paraître). 